\title{
LEGISLACIÓN, COMMON LAW, Y LA VIRTUD DE LA CLARIDAD
}

\author{
LEGISLATION, COMMON LAW, AND THE VIRTUE OF CLARITY
}

\begin{abstract}
PAul Yowell*
RESUMEN: El presente ensayo considera la claridad normativa como supuesto básico del Estado de Derecho. La promoción de la claridad normativa requiere, de acuerdo al autor, de la existencia de un sistema de separación institucional de poderes en el cual sean diferenciados los órganos llamados a dictar las normas de aquellos llamados a aplicarlas. De esta forma se protegerían los principios de irretroactividad, generalidad y conocimiento del derecho, todos ellos directamente vinculados al concepto de claridad. El autor plantea que esta concepción se opone a aquella que concentra en los jueces facultades legislativas y jurisdiccionales. La razón esencial de esta oposición es que las sentencias judiciales, en cuanto fuente de derecho, pueden generar espacios de incerteza y retroactividad, vicios ambos incompatibles con una sana concepción de Estado de Derecho.
\end{abstract}

Palabras clave: Estado de Derecho, separación de poderes, revisión judicial, deferencia, claridad.

ABSTRACT: This essay considers the virtue of clarity as a core element of the rule of law. According to the author, its promotion requires a system of separation of powers in which the institution called to create the law is different than the organ called to apply it. In this way, the values of prospectivity, generality and promulgation -directly related to the idea of clarity- are correctly protected and achieved. In contrast, a regime in which the courts have authority not only to adjudicate cases, but also to legislate through judicial decisions, creates areas of uncertainty and retroactivity, both legal vices totally rejected by the very notion of the rule of law.

Key words: rule of law, separation of powers, judicial review, judicial deference, clarity.

\section{INTRODUCCIÓN}

Entre los elementos que componen la concepción de Estado de Derecho, el concepto más esquivo, así como el más central y estratégico, es la claridad. La claridad es un elemento central y estratégico porque supone y da sentido vital a otros elementos que componen la noción de Estado de Derecho, tales como la necesidad de promulgación, irretroactividad, generalidad y estabilidad de las normas jurídicas. Claridad es un concepto esquivo porque, primero que todo, mantiene una especial relación con la idea de generalidad. Las leyes refieren clases generales de personas y acciones, más que casos particulares; solo en

* Lecturer in Law, New College, Oxford University. Email: paul.yowell@law.ox.ac.uk.

BA JD Baylor, BCL MPhil Oxford. Este artículo corresponde a una traducción realizada por Gonzalo Candia. Abogado, Licenciado en Derecho, Pontificia Universidad Católica de Chile, SJD (c) Universidad de Georgetown. Profesor Asistente Adjunto de Derecho Constitucional y Derechos Humanos, Pontificia Universidad Católica de Chile (gfcandia@fulbrightmail.org). El traductor agradece la autorización y asistencia proveída por el Profesor Yowell durante el proceso de edición. 
esa forma el derecho puede coordinar y orientar la conducta de la comunidad política y ser debidamente comprendido por sus miembros. Al mismo tiempo, el derecho debe gozar de algún grado de especificidad por las mismas razones señaladas. Mi tesis es que la claridad constituye un aristotélico justo medio entre una regulación excesivamente general y una excesivamente específica. Asimismo, la claridad es también esquiva porque ella genera ciertas tensiones al interior del objetivo de lograr justicia de acuerdo al derecho. En algunos casos la aplicación de la ley puede producir injusticias, ya sea porque el derecho en sí es injusto, o porque la aplicación de los términos generales de una ley puede producir, en la práctica, efectos injustos para una de las partes. Pero, ¿no es esto contradictorio con la idea misma de que la justicia requiere de la aplicación imparcial de los términos generales de la ley a un caso concreto sin hacer juicios discrecionales o de mérito acerca del carácter de la norma? ¿No es el papel del juez aplicar e interpretar de buena fe la legislación, dejando las referidas consideraciones de justicia y mérito de la misma al Poder Legislativo o a otro órgano constitucionalmente autorizado para legislar?

Los elementos que conforman el Estado de Derecho no solo se refieren a las expresiones verbales de las leyes, o a las leyes como un conjunto de reglas cuyo contenido debe ser formulado en ciertos términos ${ }^{1}$. El Estado de Derecho es una característica propia de todo sistema jurídico correctamente ordenado, orden que debe manifestarse en sus instituciones y procedimientos ${ }^{2}$. En el listado de elementos constitutivos del Estado de Derecho propuesto por Lon Fuller, el elemento central que define al Estado de Derecho es la "congruencia entre la decisión estatal y la regla promulgada"3. John Finnis adopta similar posición al momento de concluir la lista de los elementos que, en su opinión, son constitutivos del Estado de Derecho. Así, Finnis señala que aquellos que tienen la autoridad para administrar y aplicar el derecho en su calidad de funcionarios deben ser susceptibles de ser fiscalizados en "(a) el cumplimiento de las reglas aplicables a sus actuaciones y (b) en la

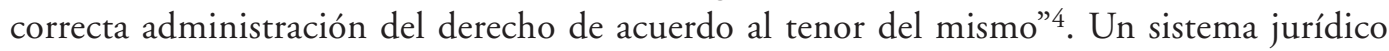
subsiste en el tiempo estableciendo reglas en el presente para ser aplicadas en el futuro. Esta manifestación institucional del Estado de Derecho es requerida por los ciudadanos para planificar sus conductas con anterioridad y de acuerdo a leyes claramente promulgadas. La claridad y la predictibilidad de aquellas leyes, valores ambos íntimamente relacionados, se verían notoriamente afectadas si un juez, so pretexto de obtener justicia en un caso concreto, resuelve un asunto de manera inconsistente con la regla legal previamente declarada.

\section{UNA PRIMERA APROXIMACIÓN AL PROBLEMA: ARISTÓTELES Y EL CONCEPTO DE EQUIDAD}

La observación realizada por Aristóteles acerca de la tensión entre justicia y equidad constituye un interesante punto de partida para una posterior reflexión acerca de la virtud de la claridad y su relación con la generalidad, característica esencial de las leyes:

\footnotetext{
${ }^{1}$ Finnis (1980) p. 271.

${ }^{2}$ Finnis (1980) p. 271

${ }^{3}$ Fuller (1969) pp. 21-81.

${ }^{4}$ Finnis (1980) pp. 270-271.
} 
"Las dificultades surgen del hecho que lo equitativo es justo no ante los ojos de la ley, porque lo equitativo no es sino una rectificación de la justicia legal. Y la razón de aquello es que las leyes son redactadas en términos generales, por lo que existen ciertos casos particulares respecto de los cuales no se puede pronunciar correctamente. Donde sea necesaria una declaración general (...) las leyes van a describir la mayoría de los casos, aunque esto no significa ignorar la presencia de elementos de error. Pero este error no radica en el derecho o en la ley, sino en la naturaleza del caso. Ello porque es realmente imposible abarcar completamente la diversa variedad de las acciones humanas" 5 .

Para Fuller, la generalidad es el primer elemento constitutivo del Estado de Derecho ${ }^{6}$. Hart explica que el derecho usa "regla generales, estándares, y principios" y este "es aplicable a clases de personas, actos, cosas, y circunstancias; y el éxito de su aplicación sobre vastas áreas de la vida social depende de la capacidad que este tiene para reconocer actos particulares, cosas, y circunstancias como instancias de las clasificaciones generales que el derecho efectúa"7. Redactar normas jurídicas en términos generales parece una labor a simple vista sencilla, pero la experiencia pone en evidencia algo muy distinto. La dificultad y la complejidad implícita en la redacción de una ley es consecuencia de la textura abierta del lenguaje humano, de la inmensa e impredecible variedad de comportamientos humanos y, tal como Hart lo señala, de la relativa indefinición del propósito legislativo ${ }^{8}$. En este sentido, Aristóteles explica que como los legisladores no pueden proveer una solución correcta para cada caso, ellos deben redactar las leyes considerando solo el caso general. Lord Bingham, usando un lenguaje más moderno, señala: "los textos legislativos no pueden ser redactados teniendo en mente casos excepcionales. Ellos deben considerar reglas de carácter general... Una regla de carácter general implica trazar una línea (que distinga entre el caso general y los casos excepcionales que puedan surgir), y es función del parlamento decidir dónde esta línea debe ser trazada. La existencia de esta línea inevitablemente trae como consecuencia la posibilidad de que surjan casos difíciles [hard cases] al lado equivocado de la línea"

Las leyes son, por tanto, necesariamente imperfectas. Este es el punto de partida de la concepción aristotélica de equidad. Considérense las traducciones de dos pasajes clave de la obra del Estagirita, en donde el segundo sigue inmediatamente al primero:

"Es correcto que cuando los términos de una ley sean generales pero el caso particular constituya una excepción a la regla -situación en el cual la regla legal es inadecuada o errónea en virtud de su generalidad- se deba rectificar el defecto que el propio legislador hubiese corregido si hubiese tenido conocimiento del mismo"10.

\footnotetext{
${ }^{5}$ Aristóteles, Ética a Nicómaco V10 1137b11-19 (el énfasis es nuestro).

${ }^{6}$ Fuller (1969) p. 21.

${ }^{7}$ Hart (1994) p. 124.

${ }^{8}$ HaRT (1994) pp. 128-130.

${ }^{9} R$ (Animal Defenders International) v. Secretary of State for Culture, Media, and Sport (2008).

${ }^{10}$ Aristóteles, Ética a Nicómaco, V 1137b22-33 (trad. Welldon)
} 
"Cuando el derecho habla universalmente, y surge un caso el cual no es cubierto por una declaración general, es correcto, donde el legislador falla por falta de regulación, corregir la omisión, diciendo aquello que el mismo legislador habría decidido en caso de haber conocido de la situación"11.

Una dificultad inicial con la doctrina de Aristóteles es que dentro de ella existe una tensión entre su primera afirmación reconociendo que el carácter general de las leyes implica que estas no pueden correctamente cubrir cada caso particular y, su segunda afirmación, en la cual reconoce que el legislador podría haber previsto una solución para un caso particular en que la aplicación de la ley requiriese la corrección de la equidad. Una dificultad adicional surge en lo que respecta a las virtudes de claridad, irretroactividad y congruencia entre la decisión de la autoridad y la regla previamente declarada. ¿Está Aristóteles sacrificando estos valores, y junto a ellos al Estado de Derecho mismo, para aplicar la ley de acuerdo a los principios de equidad en cada caso concreto? Ninguna respuesta puede ser dada a las interrogantes y dificultades generadas por este punto sin una teoría general acerca de las instituciones jurídicas (legislaturas, cortes...) y el papel que cada una de esas instituciones representa dentro del esquema de la separación de poderes. Y no existe posibilidad alguna de estudiar la compleja relación entre derecho, equidad, jurisdicción y hermenéutica legal sin previamente analizar complejas cuestiones cuya definición va más allá de las posibilidades de este ensayo.

Las secciones IV y VI analizarán desafíos modernos a la noción de Estado de Derecho que yerran al momento de demarcar apropiadamente el rol distintivo de los tribunales y las legislaturas. La tensión entre justicia legal y equidad descrita por Aristóteles forma parte de un desafío perenne a la noción de Estado de Derecho, cuya resolución no es fácil. Sin embargo, analizando este desafío en un contexto más amplio, como lo haré en las secciones II, III y V de este ensayo, la tensión descrita puede ser reducida.

La discusión en Santo Tomás de Aquino: tensión entre la particularidad de los casos concretos y la generalidad de la ley

Analizando la cuestión acerca si las leyes deben ser redactadas en términos particulares antes que generales, Santo Tomás de Aquino llega a la misma conclusión planteada por Aristóteles, proponiendo una justificación similar ${ }^{12}$. Santo Tomás construye su concepción citando la fuente autorizada del Digesto de Justiniano: "Las leyes están llamadas a regular los hechos que frecuentemente ocurren; luego, las leyes no están destinadas a regular situaciones excepcionales"13. Santo Tomás concuerda con Aristóteles en términos generales acerca de la interpretación en equidad, señalando que en ciertos casos las sentencias "no deben ser dictadas de acuerdo a la letra de la ley, sino de acuerdo al concepto de equidad que el legislador considere" 14 . De esta forma, Santo Tomás introduce una pequeña pero significativa diferencia, observando que "incluso en aquellos casos el legislador podría haber resuelto el

\footnotetext{
${ }^{11}$ Aristóteles, Ética a Nicómaco, V 1137b22-33 (trad. Ross).

12 S.T. I-II q. 96 a. 1. Aquí y a lo largo de este ensayo, el sistema de cita utilizado es usado para la Summa Theologiae de Santo Tomás de Aquino; las referencias corresponden a una de las cuatro partes (I,I-II,II-II,III), questiones (q) y artículos (a).

${ }^{13}$ Digesto I, título 1 , leyes 3 y 4.

${ }^{14}$ S.T. II-II q. 60 a. 5.
} 
caso de una manera diferente; y si él hubiese previsto el caso, él podría haber proveído el derecho aplicable" 15 .

Mientras Aristóteles describe la tarea del juez que hace uso de la equidad para resolver un caso como una corrección o rectificación de la ley, Santo Tomás analiza el punto desde la perspectiva de la dispensa de la aplicación de la ley. Leyes generales "admiten dispensa en aquellos casos en que la observación estricta de la letra de la ley frustra la intención del legislador" ${ }^{16}$. Esta afirmación viene a continuación de la sección destinada por Santo Tomás a la cuestión de si aquellos sujetos al derecho pueden actuar en contra de este. Ofreciendo un muy justificado sí a esta interrogante, Santo Tomás explica el papel que representa el legislador humano, así como sus limitaciones:

"Como el legislador no puede contemplar todos los casos particulares, él dirige su accionar hacia el bien común y dicta leyes considerando aquellas cosas que comúnmente ocurren. Luego, nadie está obligado a observar una ley cuya aplicación en el caso concreto pueda ser dañina para [el bien común]..."

"No existe sabiduría humana capaz de contemplar cada caso particular [que pueda surgir en el contexto de la aplicación de la ley]. Nadie puede adecuadamente expresar aquello en palabras. Incluso si el legislador pudiera contemplar todos los casos, para evitar confundir a los ciudadanos, resultaría más beneficioso no expresarlos. Por el contrario, el legislador debe dictar leyes considerando aquello que generalmente ocurre"17.

De esta forma, Santo Tomás evita referirse a la aparente inconsistencia entre la equidad y la generalidad del alcance de la ley que es posible advertir en Aristóteles. Aristóteles ha referido que (i) las leyes tienen alcance general y que aplican imperfectamente en algunos casos (estando el "error" ni en la ley misma ni en la acción del legislador sino en la naturaleza misma del problema) y (ii) que cuando la ley no provee la solución correcta para un caso concreto, el legislador yerra por un exceso de simplicidad en la redacción de los términos de la ley (traducción de Ross), o adoptando una regla "inadecuada o errónea en virtud de su generalidad” (Welldon). Para Aristóteles la solución al problema está dada por la aplicación de la corrección que el legislador, con anticipación, podría haber incluido en la ley. Parece implícito en la proposición (ii) y en el principio aristotélico de aplicación/interpretación que es posible para el derecho positivo -leyes adoptadas por una legislatura- proveer una solución para cada caso de tal modo que la aplicación de la ley sea siempre justa o "correcta" y esto parece contradictorio con la proposición (i). Santo Tomás, sin embargo, puede argüir que la legislación contiene preceptos de alcance general que pueden producir resultados equivocados al momento de ser aplicados, aun cuando ellos fueran formulados apropiadamente. La función del juez, en la visión de Santo Tomás, sería no necesariamente corregir o rectificar el texto de la ley y resolver en conformidad a esta nueva versión de la ley, sino proveer una dispensa de la aplicación del tenor literal de la norma.

\footnotetext{
${ }^{15}$ S.T. II-II q. 60 a. 5.

16 S.T. II-II q. 100 a. 8.

17 S.T. I-II q. 96 a. 6 (el énfasis es nuestro).
} 
Santo Tomás considera la existencia de un daño sustancial cuando refiere que las leyes no deben ser aplicadas si ellas pudiesen atentar contra el bien común. De allí la necesidad de dejar sin ejecución una ley. El ejemplo que nos da es el siguiente: una ley requiere el cierre de las puertas de la ciudad cuando se produzca una batalla. Sin embargo, las puertas deben ser abiertas en medio del fragor del combate si los defensores de la ciudad, escapando del enemigo, retornan a la ciudad. Esta decisión "contraria al tenor de la ley busca la preservación del bien común, lo que es previsto por el legislador" 18 . Pero no cualquiera tiene la facultad para determinar cuándo la ejecución de una ley puede causar un daño a la comunidad $^{19}$. La potestad para dispensar leyes la poseen aquellos investidos en autoridad, porque sería "más peligroso" entregar esta potestad a la discreción de cada individuo, que podría violar la ley, dejándola sin ejecución, basado en que su observancia podría evitar un bien o acarrear un mal para la comunidad ${ }^{20}$. Asimismo, Santo Tomás parece sugerir que la ley escrita debe ser ejecutada a menos que hubiese sido obtenida una autorización previa de la autoridad para no observarla, o bien en caso de un peligro que aparece repentinamente ${ }^{21}$.

Para Santo Tomás el carácter general de la ley positiva está implícito en su definición misma como (i) una ordenación (dictado, prescripción, proposición) de la razón práctica (ii) en vista del bien común (iii) realizada por quienes tienen a su cargo el cuidado de la comunidad, y la cual es (iv) sujeta a promulgación ${ }^{22}$. La ley, de esta forma, es "regla y medida" dirigida a las personas para que actúen de una determinada forma. En cuanto dictado de la razón práctica, las leyes señalan aquello que debe ser hecho; ellas "ordenan y prohíben" 23 (así como permiten ${ }^{24}$ ); ellas dirigen una persona que está deliberando qué hacer, ayudándole a definir si realizar o no una acción. En cuanto prescripciones de una autoridad, las leyes contienen mecanismos que sancionan su infracción, todo aquello con el propósito de inducir su cumplimiento y asegurar a quienes respetan la ley que no queden abandonados a la acción de criminales, o a la acción de aquellos que buscan tomar ventajas personales antes que realmente cumplir con la ley ${ }^{25}$.

Las leyes deben ser promulgadas en una forma tal que permita su conocimiento a todas "las personas obligadas, lo que es propio del derecho"26. Esto está directamente vinculado con la visión moderna de que la ley debe disponer solo para el futuro, no pudiendo ser retroactiva en su aplicación. Santo Tomás afirma que "la promulgación de una ley en el presente se proyecta hacia el futuro a través de la permanencia de las palabras escritas, las cuales siempre requieren ser promulgadas" 27 . Nosotros adquirimos conocimiento de la ley a

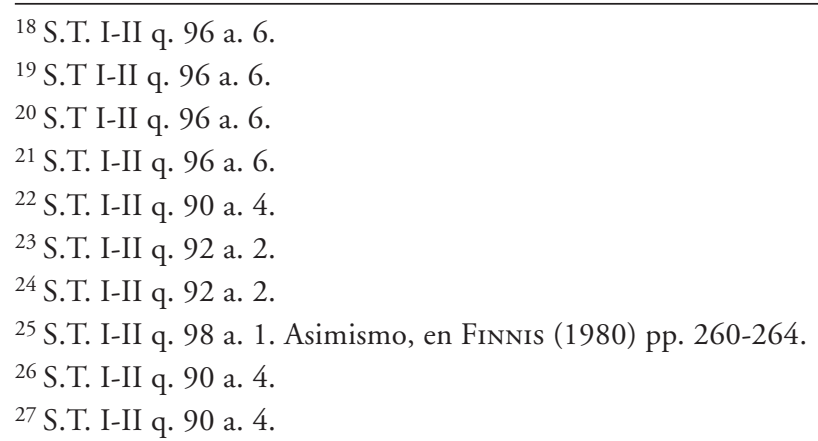


través de su lectura porque la ley es escrita ${ }^{28}$. "Y la promulgación de la ley es necesaria para producir sus efectos"29.

En cuanto "las leyes deben ser dictadas para el bien común de los ciudadanos y no para el beneficio de unos pocos" 30 , ellas deben ser proporcionadas al bien común. El propósito de la ley es la promoción del bien común, y "cualquiera sea el fin de la misma debe ser proporcionado al bien común"31. Como el bien común está constituido por muchos elementos, las leyes necesitan ser aplicables a esa generalidad de elementos que pueden ser personas, materias, tiempos, y lugares:

"Si hubiera tantas reglas o medidas como cosas regladas o medidas, ellas dejarían de ser útiles por cuanto la utilidad de dichas reglas y medidas es que son aplicables a muchas cosas. Por tanto, dichas leyes no tendrían utilidad si ellas no pudieran ser aplicadas más que a un solo caso particular" 32 .

Junto con ser promulgadas y redactadas en términos generales, las leyes deben ser puestas en conocimiento de la comunidad [manifestatio], evitando toda oscuridad que confundiera a los destinatarios de las normas, "previniendo cualquier daño que pudiera surgir de las leyes en sí mismas" 33 . Esto nos lleva a volver al tema que referíamos anteriormente: a la tensión existente entre equidad y aplicación estricta de la ley. "No es posible expresar con palabras todas las situaciones cubiertas (...) incluso si el legislador pudiera contemplar todos los casos, no debiera mencionarlos todos, para evitar confundir a los ciudadanos. El legislador debe dictar leyes considerando aquello que generalmente ocurre" 34 .

Muchas comunidades políticas han considerado (i) sus leyes y reglas inmutables o (ii) no han establecido mecanismos que permitan regular la introducción de cambios en sus leyes a través de funcionarios, instituciones o procedimientos. Existe algo de esto en la doctrina tradicional del common law; de acuerdo a algunos autores, el common law es descubierto, no creado, y consiste en la aplicación de una gama de diversas normas, las que van desde principios de razón a costumbres inmemoriales ${ }^{35}$. De acuerdo a Tomás de Aquino, las leyes humanas son dictadas, no descubiertas, y ellas requieren de revisión cada cierto tiempo por dos razones. La primera es el progreso en el área del entendimiento moral. Así como ocurre en las ciencias teóricas, donde los científicos van corrigiendo el trabajo de sus antecesores, en materias prácticas existe también un esfuerzo continuo para mejorar su comprensión ${ }^{36}$. De esta forma, si el legislador anterior dicta leyes imperfectas, deficientes en muchos sentidos, ellas pueden ser revisadas posteriormente por los sucesivos legislado-

\footnotetext{
28 S.T. I-II q. 90 a. 4.

${ }^{29}$ S.T. I-II q. 90 a. 4.

30 S.T. I-II q. 96 a. 1.

31 S.T. I-II q. 96 a. 1.

32 S.T. I-II q. 96 a. 1.

33 S.T. I-II q. 95 a. 3.

34 S.T. I-II q. 96 a. 6.

35 Postema (1986) ch. 1.

36 S.T. I-II q. 97 a. 1.
} 
res, todo ello con el objetivo de preservar el bien común de la comunidad ${ }^{37}$. La segunda razón es que las leyes requieren ser revisadas para responder a "las cambiantes condiciones de los seres humanos" porque "dicho cambio es conveniente para las personas de acuerdo a sus distintas circunstancias" 38 . Sin embargo, las leyes no deben ser revisadas para mejorar "cualquier aspecto de estas", porque el cambio en sí mismo envuelve algún grado de detrimento para el bien común. En ese sentido, la costumbre, en cuanto fuente de derecho, "resguarda la observancia de ciertas reglas"; luego, es sumamente grave si alguien no sigue los dictados de una costumbre, y la fuerza vinculante del derecho disminuye en la medida que las costumbres son abolidas" 39 . Por tanto, las leyes deben ser modificadas solo si la revisión implica un beneficio mayor que el detrimento causado por el cambio impuesto a las formas de vida de las personas. Por ejemplo, dicho mayor beneficio operaría en los casos en que "las leyes existentes fuesen manifiestamente injustas" o si la observancia de las leyes fuera extremadamente dañina para la comunidad, o si la nueva regulación representara un "gran y claro beneficio" 40 .

Tomás de Aquino no considera en su teoría la forma que una legislatura deba adoptar o los detalles relativos a esta. Su argumento es aplicable a una comunidad política en la cual la función legislativa es ejercida "por el pueblo entero" (pensemos en la Asamblea en Atenas) o a una comunidad en la cual existe una persona a cargo del cuidado del pueblo ${ }^{41}$. Sin embargo, la teoría de Tomás de Aquino asume que la función de legislar está institucionalmente separada de la función de juzgar casos particulares. Es así que el Aquinate, respondiendo al argumento de que es mejor entregar la función de aplicar justicia a los jueces antes que a leyes generales, cita a Aristóteles: "es mejor que el derecho dirija todas las cosas que entregarlas a la discrecionalidad de los jueces" 42 , adoptando como propias las tres razones señaladas por el Estagirita:

“[1] Es mucho más fácil que un número limitado de personas dicte leyes adecuadas que las muchas personas requeridas para dictar una sentencia; [2] la legislación debe ser producto de un largo período de preparación, mientras que las sentencias judiciales deben ser dictadas en circunstancias de extrema urgencia; [3] y, las decisiones del legislador, que conciernen materias de carácter general y son vinculantes hacia el futuro, son menos susceptibles de ser corrompidas por parcialidad, mala voluntad o algún otro deseo que surja en relación con los intereses de los litigantes en una causa judicial. Pocas personas entienden que una sentencia judicial es realmente justa si esta no está basada y decidida en base al derecho"ł3.

\footnotetext{
37 S.T. I-II q. 97 a. 1.

38 S.T. I-II q. 97 a. 1.

39 S.T. I-II q. 97 a. 2.

40 S.T. I-II q. 97 a. 2.

${ }^{41}$ S.T. I-II q. 90 a. 3.

${ }^{42}$ S.T I-II q. 95 a. 1.

${ }^{43}$ Esta traducción está tomada de Finnis (1998) pp. 250-251. El énfasis es nuestro.
} 
Por tanto, y usando la expresión de Finnis, "en cuanto sea posible deben existir leyes destinadas a definir anticipadamente cómo resolverán los jueces. De esta forma, las materias entregadas a la discrecionalidad de los jueces deben ser reducidas al máximo” ${ }^{4}$.

\section{EL PROBLEMA DE LA LEY INJUSTA EN EL ESTADO DE DERECHO: LÍMITES DE LA INTERVENCIÓN JUDICIAL}

Una de las críticas más fuertes dirigidas en contra de la teoría del derecho natural es que ella, mezclando el razonamiento moral con el jurídico, afecta el principio de certeza jurídica, en cuanto promueve que tanto jueces como ciudadanos acepten una ley como válida solo si ella se conforma a la moral ${ }^{45}$. Esta crítica deriva de un incorrecto entendimiento de una proposición atribuida a Santo Tomás: lex injusta non est lex: ley injusta no es ley. La tesis de Santo Tomás acerca del derecho injusto requiere una mayor precisión en sus términos; por ejemplo, él califica las leyes dictadas por un tirano para beneficio propio "no como leyes simpliciter, sino como una forma de perversión del derecho" 46 . Lo que Tomás de Aquino quiere decir en este pasaje es que las normas dictadas por el tirano no constituyen el concepto central de derecho tratado en la parte II de la Suma; en su sentido focal, la ley es promulgada por la autoridad competente para la promoción del bien común. Considerando leyes injustas como casos defectuosos de lo que una ley debe ser, Tomás de Aquino sigue el método basado en un "caso central" empleado por Aristóteles al momento de distinguir entre "un amigo" (caso central) y un "socio", o entre una persona meramente conocida y un "amigo por conveniencia" 47 .

Tomás de Aquino no señala de forma explícita que "la existencia de la ley es una cosa; su mérito o demérito es otra" ${ }^{48}$. Él toma esto por algo obvio, y frecuentemente se refiere a las "leyes injustas" como entidades existentes, como problemas reales que deben ser solucionados. Por tanto, Santo Tomás acepta, en palabras de Hart, que "no necesariamente se sigue del hecho que una regla infrinja estándares de moralidad que aquella no sea una regla de derecho" ${ }^{49}$. El tratamiento que Santo Tomás da a la necesidad de promulgar las leyes y de cambiarlas de tanto en tanto muestra que él también conviene con Hart que "el hecho que una regla sea moralmente deseable no la hace necesariamente una regla de derecho" 50 . En cuanto las leyes existentes pueden ser deficientes por el débil razonamiento moral detrás de ellas o por no responder a las cambiantes necesidades sociales de una época, ellas requieren ser cambiadas por medio de un acto positivo, de tal manera que el contenido de esas leyes sea moralmente deseable. Adicionalmente, para que una ley produzca sus efectos es necesario que ella sea promulgada. A través de su tratamiento del derecho y de la ley, Tomás de Aquino es consciente de que el contenido específico de las leyes es definido, al

\footnotetext{
${ }^{44}$ Finnis (1998) p. 250.

${ }^{45}$ HaRT (1994) p. 156; pp. 207-212.

46 S.T. I-II q. 92 a. 1. Asimismo, en Finnis (1980), pp. 363-364.

${ }^{47}$ Aristóteles, Ética a Nicómaco VII 1157a 30-3.

${ }^{48}$ Austin (1832) p. 157.

${ }^{49}$ Hart (1958) pp. 593-599.

${ }^{50}$ Hart (1958) pp. 593-599.
} 
ser promulgado por escrito, en fuentes socialmente reconocidas, tales como la legislación. Por tanto, Hart estaba equivocado cuando sostenía que la tradición tomista entendía que "ninguna norma injusta puede tener el carácter de ley", "negando así validez legal a norma injusta", calificando dichas normas como "no válidas" y "en sentido alguno derecho" 51.

Tomás de Aquino sostiene que algunas veces los ciudadanos no están obligados a obedecer leyes injustas y que los jueces algunas veces no deben aplicarlas. Pero ello también es reconocido por Hart y la tradición moderna del positivismo jurídico. De hecho, Hart elogia el positivismo en cuanto, mucho más que la tradición del derecho natural, es capaz de permitir que las personas claramente puedan tomar conciencia que existen ciertas leyes injustas, de tal forma de poder decir: "esto es una ley, pero ella es tan injusta que no merece ser aplicada u obedecida" 52 . Por tanto, la teoría del derecho natural y Santo Tomás no se diferencian de la moderna tradición positivista en cuanto la "teoría de las fuentes" 53 , sino en el hecho que la teoría del derecho natural considera que el establecimiento de un sistema jurídico es una exigencia universal de moralidad. Donde Finnis señala que "hay bienes humanos que pueden ser asegurados solo a través de las instituciones del derecho, y exigencias de la razonabilidad práctica que solo aquellas instituciones pueden satisfacer" ${ }^{54}$, la moderna tradición positivista representada, por ejemplo, por Joseph Raz, sostiene que es discutible la cuestión sobre si una sociedad requiere necesariamente un sistema jurídico y si su adopción permitirá mejorar aquella sociedad.

Por el contrario, Santo Tomás y Finnis señalan que la dictación de normas positivas para regular ciertas interacciones y relaciones humanas es necesaria para actuar correctamente de acuerdo a las exigencias universales de moralidad, como aquellas que obligan a tratar a todas las personas de forma justa ${ }^{55}$. Resumiendo, las comunidades humanas necesariamente requieren de leyes; y aquellas deben ser promulgadas en forma tal que sean claras y entendibles para quienes se encuentran sujetos a ellas. Quizá Finnis va más allá que Santo Tomás cuando refiere que el Estado de Derecho requiere la existencia de un sistema jurídico en el cual los jueces juzguen casos concretos de acuerdo a normas previamente promulgadas:

"En cuanto el proceso judicial, un principio básico de justicia exige que los litigantes (y otros actores envueltos en el proceso) sean tratados por los jueces (y por quienes tengan alguna autoridad dentro del proceso para tomar decisiones) imparcialmente, de forma tal que cada uno de ellos sea tratado de la misma forma que lo sería en frente de otro juez. Es precisamente esto lo que define al derecho como una techne racionalmente establecida que responde a un conjunto de normas positivas identificables simplemente como "fuentes" (por el hecho de haber sido promulgadas o constituidas por medio de otro mecanismo) aplicadas de acuerdo a los términos de su promulgación y publicación en la medida de lo posible, términos cuyo significado ha sido dilucidado recurriendo en el menor grado posible a elementos que, por no

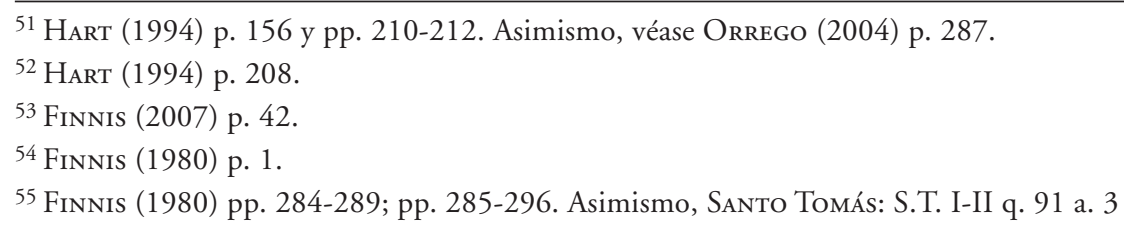


estar contenidos en el acto constitutivo de la norma, pueden generar consideraciones diferentes entre jueces distintos" 56 .

Finnis reconoce que "la separación del razonamiento legal del razonamiento moral" nunca podrá ser completa ${ }^{57}$, y que el razonamiento jurídico permite que las reglas que constituyen el derecho positivo sea "permeadas por los principios de la razonabilidad práctica” de forma tal que ellas puedan derivar en formas diversas de aquellas buscadas por la autoridad oficial y que, al menos en algunos sistemas, este principio pueda permitir a los jueces dejar de aplicar leyes injustas ${ }^{58}$. Sin embargo, el análisis jurídico "es (al menos en su parte más importante) un tipo de razonamiento técnico, no moral"59:

“Como todo razonamiento técnico, este concierne un propósito específico, un estado definitivo obtenido por medio de la eficiente disposición de los medios a un fin particular. El fin particular en este caso es la resolución de disputas (y otras alegaciones de conductas contrarias a la ley) a través de una norma directiva (precisa y directa)... Por tanto, las herramientas distintivas del derecho son: términos definidos y reglas específicas, con suficiente y necesaria claridad y concreción, con el objetivo de establecer las "líneas brillantes" que permitan transformar muchos problemas legales de la vida diaria en problemas de fácil solución. Las definiciones legales y las reglas proveen al ciudadano, a los abogados y a los jueces de un algoritmo para decidir cuantos problemas legales sea posible -en principio cada problema- con un sí (o un no): este curso de acción podría ser (o podría no ser) permitido por el derecho, este acuerdo es válido, este contrato está perfeccionado, aquellos daños son económicamente compensables y el resto no, y así. En la medida de lo posible, el derecho provee fuentes para el razonamiento -leyes, reglamentos, reglas de common law, y costumbres- las que son capaces de categorizar (...) disputas como correctas o incorrectas, para mejor o para peor..." 60 .

En otra sección Finnis explica que esta aproximación al derecho positivo está conectada a la fuerza invariable de las obligaciones legales: desde una perspectiva jurídica no existen grados de validez legal u obligación ${ }^{61}$. Este principio formal tiene una contraparte metodológica en el postulado de que no existen obligaciones legales contradictorias o en conflicto entre sí; luego, el papel de los abogados es siempre definir "los límites de cada obligación legal potencialmente aplicable, de modo tal que la única obligación legal sea identificada, y todas las demás pretensiones rechazadas (pretensiones existentes respecto de la misma situación) ${ }^{62}$. Esto requiere de una constante especificación de las reglas legales

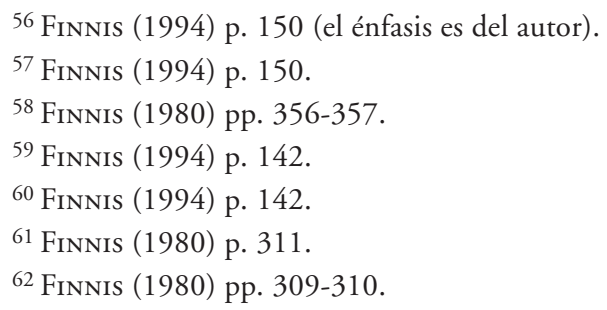


aplicables, con sus correspondientes listados de condiciones y excepciones que constituyen el "incansable esfuerzo para dotar a la norma de suficiente definición y coherencia"63:

"La famosa inflexibilidad de la ley va mucho más allá de lo que se podría suponer si se consideran, por ejemplo, conocidos ejemplos de prohibiciones propias del derecho Penal, las cuales son tan franca, ingenua, o sabiamente redactadas que todos pueden concordar que una conducta es encomiable o, al menos, aceptable. Más que por esas razones, la inflexibilidad del derecho está fundada en la invariabilidad de la norma legal que impone una obligación; y en sistemas legales maduros esta inflexibilidad debe ser la principal consecuencia de un exquisito refinamiento y precisión en la redacción de las leyes" 64 .

En un claro contraste con Finnis, Raz niega que el razonamiento jurídico sea una forma de razonamiento técnico; tal como lo veremos en la próxima sección, Raz admite que el razonamiento moral juega un papel mucho más importante en la decisión judicial de aquel que Finnis considera como deseable o apropiado en un sistema legal maduro.

\section{LA NOCIÓN CONTEMPORÁNEA DE ESTADO DE DERECHO Y EL PAPEL DE LA DISCRECIONALIDAD JUDICIAL}

En su ensayo de 1979 Raz define la noción del Estado de Derecho desde una perspectiva normativa y evaluativa. Raz señala que en su sentido literal, la expresión Estado de Derecho significa "(1) las personas deben estar sujetas al derecho y obedecerlo, y (2) el

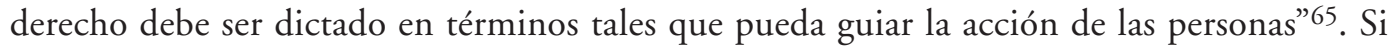
este concepto considera los términos utilizados en su sentido normalmente aceptado, Raz procede, en su propia voz, a describir el Estado de Derecho como un ideal de carácter moral, que posee una cierta virtud. Raz indica que la intuición básica a partir de la cual el Estado de Derecho proviene es que "el derecho debe ser capaz de orientar el comportamiento de aquellos que están sujetos a él" 66 . El concepto esencial que informa y da sustento a la noción de Estado de Derecho es el respeto por la dignidad humana, la cual supone tratar a las personas como seres capaces de planificar su futuro y dotados de autonomía, lo que implica, en la práctica, el respeto al derecho que ellos tienen de hacerlo. Luego, y siguiendo a Raz, el Estado de Derecho puede ser violado de dos maneras: "(1) cuando el derecho no permite a las personas anticipar desarrollos futuros o formarse expectativas definidas (en los casos en que los textos legales han sido vagamente redactados o bien permiten amplios espacios a la discreción de la autoridad) y (2) cuando el derecho frustra las expectativas que las personas se han formado a partir de la planificación de sus conductas conforme al dere-

\footnotetext{
${ }^{63}$ Finnis (1980) p. 311.

${ }^{64}$ Finnis (1980) p. 311.

${ }^{65}$ Raz (1979) p. 212.

${ }^{66}$ RAZ (1979) p. 214.
} 
cho vigente" 67 . La referida frustración se genera por medio de una arbitraria ejecución de la ley, de la promulgación de normas con alcance retroactivo, y otras situaciones similares.

Por lo tanto, todas las leyes deben producir sus efectos en el futuro, estar redactadas en términos claros y precisos y estar dotadas de una relativa estabilidad ${ }^{68}$. Al igual que Fuller y Finnis, Raz sostiene que la noción de Estado de Derecho tiene una dimensión institucional que requiere que los tribunales apliquen correctamente el derecho promulgado. Si los tribunales no lo hacen, el propósito del Estado de Derecho podría verse frustrado:

"Es de la esencia del derecho nacional establecer instituciones judiciales llamadas, entre otras cosas, a aplicar la ley a casos concretos, decidiendo de forma definitiva conflictos entre partes. En cuanto cualquier conflicto bajo el derecho puede ser sujeto a la decisión definitiva de una corte, es obvio que no tiene sentido que las personas ajusten sus comportamientos a la leyes si los tribunales, conociendo de un caso particular, no aplican dichas leyes o actúan de una forma diferente por otras razones. El punto puede ser aún más complejo. En cuanto los tribunales definen de forma conclusiva qué dice el derecho respecto del caso concreto, los litigantes pueden ser orientados por el derecho solo si los jueces lo aplican correctamente. Si ello no ocurre, las personas solo serán capaces de orientar sus conductas de acuerdo a las suposiciones que ellas mismas hacen respecto a las probables decisiones de los tribunales. Dichas suposiciones no estarán basadas en el derecho, sino en otras clases de consideraciones" 69.

En este punto, Raz hace una advertencia en una nota a pie de página: "Yo no estoy negando que los tribunales también produzcan derecho. El principio del Estado de Derecho es aplicable a los tribunales primariamente en su función de aplicar el derecho. En cuanto productores de derecho, los tribunales se encuentran sujetas a los mismos principios que el legislador"70. Como lo veremos más adelante, Raz considera que los jueces tienen, al menos en un régimen de common law, amplias facultades para producir derecho, existiendo una fuerte tensión entre dichas facultades y "su obligación de aplicar el derecho". Asimismo, Raz en sus trabajos más tardíos ha reconocido que los jueces tienen obligaciones que van mucho más allá de aplicar la ley.

Es en su ensayo de 1993 "Acerca de la Autonomía del Razonamiento Jurídico" donde Raz desarrolla con más profundidad su teoría acerca del razonamiento judicial y la función legislativa del juez. Las siguientes referencias están fundadas en dicho texto, pero también en otro ensayo publicado en su "Ética en el Ámbito de lo Público"71, así como en otros recientes trabajos. Raz rechaza la proposición de que el razonamiento jurídico -entendiendo por tal aquel desarrollado por los jueces- es autónomo en el sentido de ser un "tipo especializado de razonamiento técnico que obedece sus propias reglas" 72 . Dicha

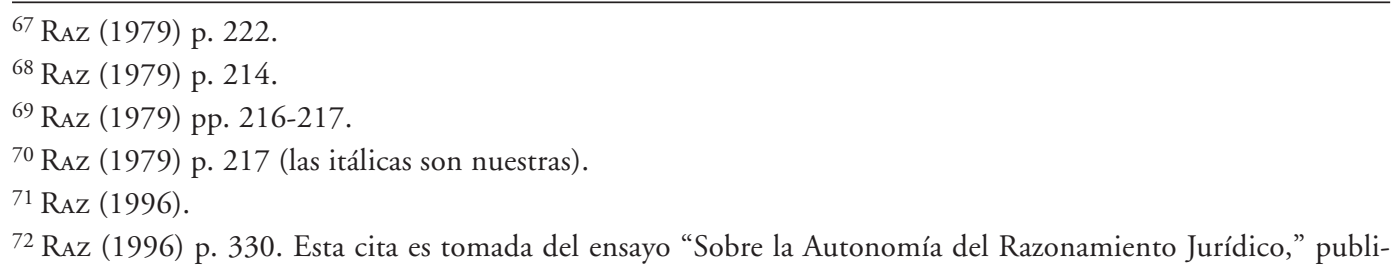


proposición, Raz arguye, es basada en una errónea analogía en la cual el razonamiento jurídico es tratado de manera similar que el razonamiento propio de los problemas prácticos de ingeniería. De esta forma, el razonamiento jurídico no está confinado a las "materias que Kant identifica dentro del reino de lo práctico, o lo que los griegos llamaron techné"73. La plomería, la navegación o la ingeniería eléctrica son áreas las cuales "obedecen sus propias reglas", y "tienen sus propios objetivos internos, que pueden ser alcanzados a través del ejercicio de una destreza específica, un ejercicio con su propia lógica interna” ${ }^{\text {" }}$. Raz señala:

"El razonamiento jurídico no es eso. No es una destreza técnica particular utilizada para perseguir un fin específico y limitado. El razonamiento jurídico tiene que ver con muchos aspectos de relaciones interpersonales y sociales y, si bien en parte debe lidiar con el manejo de reglas muy especializadas... mucho de esto no es más técnico y especializado que la moralidad misma"75.

"El razonamiento jurídico", Raz concluye, "no es sino una instancia más de razonamiento moral"76.

Existe una justificada preocupación acerca de si la mencionada conclusión es consistente con la tesis de Raz sobre las fuentes del derecho, en la cual el autor señala que "todo derecho debe provenir de una fuente", indicando con ello que "su existencia y contenido puede ser identificado solamente por medio de hechos sociales, sin referir ningún argumento de carácter evaluativo"77. El razonamiento jurídico para Raz consiste en identificar ciertas actividades e intenciones del legislador, las cuales son hechos sociales ${ }^{78}$. Sin embargo, Raz repentinamente distingue el razonamiento jurídico acerca del derecho (about the law), de aquel que es de acuerdo al derecho (according to the law $)^{79}$. El razonamiento acerca del derecho "está orientado por la teoría de las fuentes" y es "autónomo", pudiendo descubrirse el derecho aplicable en una forma "libre de consideraciones morales" 80 . Por el contrario, el

cado por primera vez en 1993. Excepto donde sea referido lo contrario, las citas alusivas a Raz han sido tomadas de dicho ensayo. Raz reafirmó su visión acerca de este tópico en "Entre Autoridad e Interpretación: Sobre la Teoría del Derecho y la Razón Práctica” (2009) pp. 376-379.

${ }^{73}$ Raz (1996) p. 334.

${ }^{74}$ Raz (1996) p. 334.

75 RAZ (1996) p. 334.

${ }^{76}$ RAZ (1996) p. 340. Existen autores aún más radicales que Raz, quienes incluso niegan el carácter jurídico del razonamiento judicial. Uno de esos autores es el norteamericano Karl Llewellyn, uno de los máximos representantes de la denominada escuela del "realismo jurídico". Llewellyn llama la atención respecto de la indeterminación e incoherencia de muchas normales legales. Estos dos problemas imposibilitarían o, al menos, harían muy difícil realizar una interpretación propiamente "jurídica” de las mismas normas. Es por ello que Llewellyn concluye que los fallos de los tribunales se explicarían realmente no por el contenido envuelto en su razonamiento, sino por "la personalidad" de quien juzga. Esto es, las creencias particulares y privadas del juez. Esta tesis, sumamente cruda en su planteamiento, fue una reacción contra la visión tradicional del derecho y la posibilidad de razonar en términos jurídicos de forma técnica. Véase: Llewellyn (1931), pp. 1242. (Nota del traductor).

77 RAZ (1996) pp. 210-211.

${ }^{78}$ Raz (1996) p. 332.

${ }^{79}$ Raz (1996) p. 332.

${ }^{80}$ Raz (1996) p. 332. 
razonamiento jurídico de acuerdo al derecho (en el particular entendimiento de Raz) es una empresa mucho más amplia, que consiste "sencillamente en un razonamiento moral" 81. Para Raz, esta propuesta no es solo perfectamente coherente con la teoría de las fuentes del derecho, sino que una consecuencia de esta: "a partir de la tesis de las fuentes... se entiende que existe mucho más razonamiento jurídico [en un análisis acerca del derecho] y, en el resto, en lo que yo he llamado razonamiento de acuerdo al derecho (...) la aplicación de consideraciones morales" 82 .

La concepción del derecho que Raz propugna representa un papel muy menor (si es que representa alguno) en la forma en la cual los jueces resuelven conflictos. Siguiendo su análisis acerca de las fuentes del derecho, Raz sostiene que "el tema objeto de la discusión es realmente la naturaleza y los límites del derecho" y agrega, con crudeza, que "nada de esto tiene que ver con aquello que los jueces deben hacer, que es resolver casos" 83 . Raz arguye que los jueces deben usar elementos de razonamiento moral no solo para cubrir las lagunas en el derecho, sino también para evaluar y, muchas veces, cambiar el derecho válidamente promulgado por el legislador: "comúnmente los tribunales ejercen discrecionalmente sus facultades para modificar reglas legales, o para hacer excepciones a la aplicación de las leyes y, donde ellas ejercen esa discreción, los tribunales deben utilizar formas de razonamiento moral para decidir si hacerlo o no, y, en caso de hacerlo, definir la forma en la que operarán" ${ }^{4}$. Para Raz, los jueces muchas veces deben no dar aplicación a una ley clara y definitiva ${ }^{85}$, o "hacer una reserva respecto de una regla legal válida, reemplazándola por otra" $"$. Aun cuando la interpretación judicial de una ley "vacíe el derecho de su contenido" podría ser perfectamente apropiada ${ }^{87}$. La subordinación del razonamiento jurídico acerca del derecho respecto del razonamiento de acuerdo al derecho en la teoría de Raz sobre la resolución de conflictos judiciales va incluso más allá. Si bien la afirmación de que "las doctrinas jurídicas están justificadas solo si ellas son moralmente justificables”. Raz agrega inmediatamente que "[dichas doctrinas] obligan solo si su cumplimiento es moralmente correcto" 88 . Nuevamente, Raz indica que "las doctrinas jurídicas... deben siempre ceder ante consideraciones morales cuando las primeras entran en conflicto con las segundas" 89 . De hecho "posiblemente todo argumento de carácter jurídico es un tipo de argumento mo-

\footnotetext{
${ }^{81}$ RAZ (1996) p. 333.

82 RAZ (1996) p. 332.

${ }^{83} \operatorname{Raz}(1996)$ p. 233.

${ }^{84}$ Raz (1996) p. 335. También en Raz (1996) p. 249.

${ }^{85} \operatorname{RAZ}(1996)$ p. 304.

${ }^{86} \operatorname{RAZ}(1996)$ p. 249.

${ }^{87}$ Reflexionando acerca de la provisión de la constitución de Israel que declara el país un Estado Judío, Raz advierte que Aharon Barak, presidente de la Corte Suprema israelí, interpretó la norma en cuestión refiriendo los valores que el judaísmo ha entregado al mundo: "el amor a la humanidad, la santidad de la vida humana, la justicia social, la equidad, la protección de la dignidad humana, la supremacía del Estado de Derecho sobre el legislador, etc.". Véase: Raz (2001), p. 37. De acuerdo a Raz, Barak "vació de contenido la cláusula constitucional que declaró a Israel un estado judío, pero aquello fue lo correcto" y "la única interpretación aceptable". Véase: Raz (1996) p. 38. El énfasis es nuestro.

${ }^{88}$ Raz (1996) p. 340.

${ }^{89}$ RAz (1996) pp. 339-340.
} 
ral, en el sentido de que los argumentos jurídicos tienen fuerza normativa solo si ellos son moralmente vinculantes" 90 .

Raz no está diciendo que la existencia de una ley debe aprobar la aplicación de un test de carácter moral. Ese es un error que Raz atribuye a algunas teorías del Derecho Natural $^{91}$. Sin embargo, nuestro autor ciertamente parece sostener que si un juez tiene la obligación de aplicar la ley, dicha ley debe pasar un test de escrutinio moral. La visión de Raz acerca de la forma en que un juez resuelve un caso es una que sitúa dentro de un conflicto jurídico un juicio de carácter moral:

"En países que cuentan con un sistema de common law, los tribunales pueden distinguir reglas del common law, aplicar doctrinas de equidad, y usar otras herramientas legales para asegurarse de que la ley que están aplicando no es injusta. Por tanto, en países como estos, todas las decisiones judiciales suponen que no existe razón alguna que pueda justificar la modificación de la ley, o su aplicación al caso"92.

Por tanto, la ley en cuanto aplicada al caso concreto es necesariamente justa (de acuerdo a la visión del juez, si él usa todas las herramientas a su disposición). Raz indica que, aun cuando el poder que tiene un juez para ir más allá de la norma legal expresa varía de acuerdo a cada país, "en todos los países regidos bajo un sistema de common law, jueces y jurados tienen una discreción legalmente reconocida, que les permite dejar sin aplicación una ley claramente promulgada por el legislador basados en razones de equidad, o bien porque infringe doctrinas constitucionales de carácter fundamental"93. Raz reconoce que existe un conjunto de reglas y doctrinas cuya aplicación requiere de un especial conocimiento y destreza, pero él asigna una importancia muy disminuida a los aspectos técnicos o a la preparación legal en su explicación de la naturaleza del razonamiento jurídico (en su vertiente de acuerdo al derecho). Esto permite resumir su postura al respecto: "el conocimiento de la ley, el entendimiento moral, y la sensibilidad están completamente entrelazados cuando nos referimos al razonamiento jurídico, ocurriendo que en algunos casos, un elemento predomina sobre los otros" 94 .

Muy cerca de la conclusión de su ensayo "Acerca de la Autonomía del Razonamiento Jurídico", Raz considera nuevamente la cuestión relativa al Estado de Derecho a través de ciertos comentarios que deben ser comparados con la posición adoptada por el autor en su ensayo de 1979, en el cual destacaba la arista institucional del concepto de Estado de Derecho:

"Una vez que se establecen esquemas legales, las personas tienen el derecho a esperar que las instituciones se sujetarán a las normas que configuran dichos esquemas, y las aplicarán. Esto ocurre porque las leyes una vez promulgadas permiten a las personas tener ciertas expectativas, permitiéndoles planificar bajo el supuesto de que dichas ins-

\footnotetext{
${ }^{90}$ Raz (2009) p. 378.

${ }^{91}$ Raz (1990) pp. 163-165.

${ }^{92}$ RAZ (2009) p. 377. En énfasis es nuestro.

${ }^{93} \operatorname{RAZ}(1996)$ p. 304.

${ }^{94}$ RAZ (1996) p. 335.
} 
tituciones estarán sujetas y darán aplicación a la ley. En gran medida esta es la forma a través de la cual el derecho produce su efecto en la sociedad. Esto no significa que las personas tengan un derecho a que la ley no cambie de forma contraria a sus intereses. Pero esto sí significa que cualquier cambio introducido en las leyes debe responder a consideraciones de justicia, tomando en cuenta las expectativas existentes" 95 .

En cuanto el establecimiento de un sistema legal incentiva a las personas a planificar suponiendo que las instituciones de dicho sistema estarán sujetas a la ley y le darán plena aplicación, la teoría de Raz acerca del carácter del razonamiento jurídico y de la naturaleza de la decisión judicial no parece ser coherente. En su ensayo de 1979 Raz señala que "es obvio que no tiene sentido que las personas ajusten sus comportamientos a la leyes si los tribunales, conociendo de un caso particular, no aplican dichas leyes o actuan de una forma diferente por otras razones" 96 . Esta afirmación debe ser contrastada con lo referido por Raz en sus trabajos más tardíos, en los cuales afirma que los jueces tienen la obligación de actuar de acuerdo a razones de carácter moral, y usualmente tienen la responsabilidad de cambiar la ley o bien de dejarla sin ejecución.

Pero suponiendo que este es un problema en Raz, ¿es esta la misma dificultad existente en las teorías acerca de la interpretación en equidad defendida por Aristóteles y Santo Tomás? Esta dificultad no es la misma porque (tal como fue explorado en las secciones I y II de este ensayo) tanto Aristóteles como el Aquinate consideran como excepcionales aquellos casos en los cuales es necesario apartarse de la letra de la ley con el objetivo de obtener una interpretación conforme a las reglas de la equidad. Ambos autores consideran la doctrina acerca de la equidad dentro de una teoría mucho más amplia, que reconoce la existencia de roles institucionales diferenciados, de un legislador que crea reglas de alcance general capaces de resolver la mayoría de los casos y que limita la discrecionalidad judicial al máximo. Tomás de Aquino generalmente afirma que la obligación de los jueces es básicamente resolver conflictos jurídicos en conformidad al derecho escrito, lo que no es sino aplicar la ley. Ni Aristóteles ni Santo Tomás creen que los jueces deban convertirse en legisladores, al menos en el sentido que Raz lo entiende. Santo Tomás estima que el uso de la equidad en la resolución de un caso consiste en la mera dispensa de la letra de la ley. Raz no solo abraza totalmente la moderna noción del common law que considera a los jueces como verdaderos legisladores, sino que también asigna un valor relativamente inferior al precedente judicial en frente de razones de tipo moral que permiten al juez el cambio de la ley.

En la sección VI demostraré que la noción del common law que considera a los jueces como legisladores desafía directamente la noción de Estado de Derecho, y que los valores de la irretroactividad de la ley, promulgación y claridad no pueden ser satisfactoriamente logrados sin la separación institucional de las funciones legislativa y judicial. La sección siguiente se centrará en analizar la importancia de la claridad de la ley y su compleja relación con la idea de generalidad, extendiendo así el análisis realizado en las secciones I y II, estableciendo al mismo tiempo las bases de lo que se planteará en la sección VI.

${ }^{95}$ Raz (1996) p. 337.

${ }^{96}$ RAZ (1979) p. 217. En énfasis es nuestro. 


\section{LA VIRTUD DE LA CLARIDAD NORMATIVA COMO CARACTERÍSTICA PROPIA DEL DERECHO LEGISLADO}

En la introducción mencioné dos razones por las cuales la virtud de la claridad es esquiva: su relación con la generalidad, y la tensión existente entre la irretroactividad de la ley y la obligación de hacer justicia en el caso concreto. Nosotros podemos ahora identificar una tercera razón. Esta razón está vinculada con la naturaleza misma del derecho que, en cuanto orientador de conductas humanas, habla a una audiencia dual. El derecho debe (i) comunicar a los ciudadanos el contenido de las obligaciones legales y las formas en las cuales ellas surgen; y (ii) instruir a los funcionarios del Estado, comúnmente de una forma mucho más detallada, acerca del contenido de esas obligaciones y la pena asociada a su incumplimiento, o las medidas aplicables en caso de infringirse alguna de dichas obligaciones ${ }^{97}$.

Siguiendo a John Gardner en su análisis acerca de este rol dual del derecho ${ }^{98}$, es posible distinguir entre la claridad textual de la ley y la claridad moral. La claridad textual implica "sencillez, sobriedad en el lenguaje, evitando el uso de complejas técnicas y fórmulas al momento de redactar el texto de una ley" ${ }^{99}$. Aunque la claridad legislativa promueve el entendimiento del texto de la ley por parte del ciudadano común, el significado textual de la misma es comúnmente definido por abogados, jueces, otros funcionarios estatales, y (de alguna manera) por los miembros de los jurados, que no tienen una educación legal previa. Gardner arguye que nosotros no deberíamos desear algo distinto a esto:

"La presunción de que el derecho es conocido por todos, o por lo menos los principales mandatos del Derecho Penal, es insostenible si insistimos en que las personas solo pueden conocer el derecho por medio de su texto (...) La mayoría de las personas tiene cosas más interesantes que hacer que familiarizarse de una verdadera avalancha de textos legales, aun cuando ellos sean fáciles de leer y entender. La mayoría de la gente (...) necesita tener solo una primera aproximación acerca de lo que el derecho dice, sin que sea necesario un conocimiento más preciso y profundo sobre ello. En estos casos, la claridad del texto de una ley, por ejemplo, es irrelevante. La claridad que es requerida en estos casos es de carácter moral" ${ }^{100}$.

La claridad moral es asegurada por medio de "la adecuada réplica en el derecho de distinciones claras y significantes, las cuales pueden ser aplicadas fuera del derecho"101, lo que incluye realidades y distinciones de carácter moral.

Gardner trata temas vinculados a la claridad textual y moral a partir de las propuestas de reforma a la ley de ofensas en contra de las personas (the Offences Against the Person Act) de 1861. La comisión legislativa para el derecho del Reino Unido propuso simplificar el lenguaje y estructura de la ley, eliminando algunos de los términos más técnicos y arcaicos,

\footnotetext{
${ }^{97}$ RAZ (1990) pp. 136-139.

${ }^{98}$ Gardner (1994) p. 512.

${ }^{99}$ Gardner (1994) p. 512.

100 GARDNER (1994) p. 512.

101 GARDNER (1994) p. 513.
} 
de forma tal que ellos fueran modificados o bien reemplazados por una terminología más moderna y sencilla. Gardner planteó que algunas de estas reformas podrían también eliminar importantes distinciones morales concernientes, entre otras cosas, al propósito de la ley y a diferentes tipos de causalidad. Dichas reformas buscaban generar mayores grados de claridad en el texto de la ley (para el ciudadano común), pero sacrificando grados de claridad moral. Gardner señaló que las reformas "más invasivas trataban de generar distinciones legales en los márgenes de la ley. Los términos técnicos deben ser tolerados"102. Gardner, asimismo, criticó el trabajo de la comisión por buscar de forma simultánea maximizar la claridad del texto de la ley y su certeza, comentando que si la certeza jurídica y la claridad en el texto de una ley son demandas del Estado de Derecho, entonces "existe un una real fuente de conflicto en este ideal [el Estado de Derecho]"103.

Esta tensión puede ser disminuida en algún grado si consideramos a la claridad como un tipo de justo medio aristotélico entre un exceso de especificidad normativa y un exceso de generalidad. Este justo medio es el mismo que refería Aristóteles cuando señalaba que la virtud del coraje es el medio entre la cobardía y la temeridad ${ }^{104}$. Es fácilmente posible sucumbir frente a la tentación de igualar claridad con especificidad. En cuanto el derecho debe orientar la conducta de las personas, este debe tener algún grado de especificidad y es entendible el deseo de avanzar en esa dirección si se analizan todas aquellas leyes cuyo contenido es obscuro o muy amplio. Sin embargo, un excesivo grado de especificidad puede atentar, al igual que en muchas otras formas de comunicación humana, contra la virtud de la claridad. Mecanismos de comunicación que multipliquen la expresión de detalles totalmente innecesarios desconocen que una audiencia siempre dispone de un tiempo limitado para leer y escuchar junto con una limitada capacidad para recordar.

El uso del lenguaje humano está (en términos de Hart) "irreductiblemente dotado de una textura abierta"105; y toda la terminología legal es, en principio, susceptible de ser considerada vaga ${ }^{106}$. Cualquier intento de eliminar potenciales vaguedades en el lenguaje del derecho, o bien eliminar la labor interpretativa de los jueces, incrementando la especificidad del texto legal, podría ser un sinsentido. Hart sostiene que aun cuando ello fuera posible, no sería deseable:

\footnotetext{
102 Gardner (1994) p. 520.

103 GARDNER (1994) p. 519.

${ }^{104}$ Aristóteles, Ética a Nicómaco VII

105 Hart (1994) p. 128.

106 Véase Endicott (2000). De acuerdo a Endicott, la vaguedad implica la pérdida del sentido claro de frontera; un término es vago cuando este es poco claro, sin importar si él refiere a un caso particular. Existen dos clases de vaguedad: (a) la vaguedad semántica y (b) la vaguedad pragmática. La primera es característica de palabras tales como "simpático" o "medio". El segundo tipo de vaguedad es posible que afecte términos más específicos o incluso técnicos. Véase: EndicotT (2000) p. 32. "Noche” y "día” no son semánticamente vagos, pero existen momentos alrededor del atardecer en los cuales es difícil decir si es aún "día”. En ese sentido, la palabra "día” es pragmáticamente vaga. Incluso términos legales muy específicos y técnicos también pueden ser pragmáticamente vagos. Endicott da el ejemplo de una regulación que exige que toda rana que fuese capturada debe ser devuelta a su medio ambiente si su tibia mide menos de 5 milímetros. Pero jesta medida debe calcularse sobre una curva o bien en línea recta? ¿Qué ocurre si una tibia mide menos de 5 milímetros y la otra más? Véase: EndicotT (2000) p. 7.
} 
"Es característica propia de la condición humana (y por tanto de la actividad del legislador) el que trabajemos bajo dos limitaciones relacionadas entre sí dondequiera que busquemos regular, sin ambigüedad y de forma previa, algún tipo de conducta por medio de estándares generales susceptibles de ser utilizados en el futuro sin ningún tipo de dirección oficial. La primera limitación es nuestra relativa ignorancia de los hechos; la segunda, es la relativa indeterminación de nuestro objetivo"107.

Tal como Hart lo nota, el legislador no puede decidir ex ante si un determinado objeto que no puede ser anticipado cae dentro de la esfera de su regulación ${ }^{108}$. Incluso podría ser conveniente que ciertos casos ubicados al límite de la regulación legal, los cuales en principio podrían ser controlados por la decisión legislativa, sean abandonados a la definición del juez por medio de una redacción vaga. Tal como Tomás de Aquino lo observa, el legislador podría razonablemente declinar el introducir distinciones y excepciones adicionales en la ley -aun cuando ello requiriera la posterior aplicación de criterios de equidad- con el propósito de evitar confundir a los destinatarios de la norma con un exceso de detalles. Además, las circunstancias políticas muchas veces obligan al legislador a optar por modelos de redacción mucho más vagos que específicos. La unanimidad en el debate legislativo es una rareza, y una técnica frecuentemente usada por los legisladores para resolver desacuerdos respecto de los términos de un proyecto de ley es aprobarlo utilizando una redacción muy general, o bien mucho más abstracta, en vez de preferir modelos más específicos. De esta forma se pospone la resolución del asunto o bien se entrega derechamente su resolución al juez. Dentro de este contexto, podría llegar a ser mucho más razonable que el legislador prefiriera una redacción representativa de una solución de compromiso, dotada de vaguedad y generalidad, a votar por una opción redactada de forma mucho más específica que quizás, en otras circunstancias, él favoreciera.

Podrían existir otras razones que favorezcan el empleo de términos generales en la redacción de una ley. Consideremos el ejemplo planteado por Gardner: una propuesta que buscaba modificar el texto de la ley de ofensa contra las personas (the Offences Against the Person Act) reemplazando el término "herir" por "perforar la piel"109. Gardner critica esta propuesta señalando que esto constituye un inútil intento de reducir un término/concepto a su condición (es) de existencia, señalando:

"No es necesario ser capaz de articular las condiciones necesarias y suficientes de algo para entender ese algo perfectamente bien. Una buena comprensión no implica la inexistencia de áreas grises. Incluso muchas de las áreas grises no son producto de un entendimiento defectuoso, o de la falta de articulación, sino parte de la cosa misma

\footnotetext{
${ }^{107}$ Hart (1994) p. 128.

${ }^{108}$ Hart (1994) p. 129.

${ }^{109}$ Gardner (1994) p. 519. Esta no fue una reforma propuesta por la comisión del derecho en Reino Unido, sino que el ejemplo tomado por Gardner del caso C (un menor) v. Eisenhower [1984] QB 331, [1983] 3 All ER 230 (DC).
} 
sujeta a análisis, la cual es constituida en parte por el papel que ella representa en nuestra global aproximación a nuestro mundo"110.

"Perforar la piel" es textualmente más específico que "herir". Sin embargo, Gardner critica la exigencia de una definición que no hace otra cosa sino replicar el problema ${ }^{111}$. Así, en las áreas donde los abogados notan un potencial conflicto interpretativo respecto de un término legal, esto podría "no tener nada que ver con la falta de claridad del lenguaje utilizado, y mucho que ver con la estructura del mundo que la ley intenta capturar"112. Si el legislador quisiera preservar el sentido amplio del término original, él quizás podría agregar la expresión "hematoma" y otras similares. Sin embargo, en esta discusión es posible apreciar tres cosas. Primero, esos términos más específicos tienen su propia periferia poco definida. Por ejemplo, cuando se usa la expresión "hematoma" ¿incluye ella el sangrado interno que no aparece visiblemente? ¿Es posible aplicar la expresión "perforar la piel” a un rasguño superficial que genera una mínima cantidad de sangre? Segundo, todo intento de eliminar elementos de vaguedad como los anteriormente descritos a través de una redacción de la ley aún más específica no resultaría exitoso del todo, debido a las limitaciones inherentes del lenguaje humano. Finalmente, dicho intento podría llegar a ser contraproducente, en la medida que la claridad del texto de la ley se vería afectada por la creciente complejidad de los términos y de la redacción empleada. El legislador, por tanto, debe escoger el nivel apropiado de generalidad en la redacción de una ley y, en este caso, parece razonable optar por la expresión "herir", una palabra que siendo vaga es aun suficientemente clara.

Determinar el justo medio entre un exceso de especificidad y un exceso de generalidad va a depender de la naturaleza del derecho en cuestión y de una variedad de otros factores contextuales. El nivel adecuado de especificidad variará dependiendo del sistema legal o del área objeto de la regulación. Así, si una ley se está refiriendo a un delito de gravedad, o bien su imposición pueda acarrear un castigo o una responsabilidad considerable, el uso de términos vagos es menos tolerable que en áreas del derecho que conciernen meras faltas, o penas muy menores, o bien bajos grados de responsabilidad. En algunos campos del derecho, tratándose por ejemplo de las regulaciones de seguridad industrial, aquellos sujetos a ese derecho consultarán las normas que lo integran con anterioridad y ordenarán sus operaciones de forma tal que puedan cumplir los mandatos de la ley. Leyes exhaustivamente redactas podría ser la forma más apropiada para enfrentar situaciones que pudieran originar daños o que pudieran amenazar la seguridad de las personas. Existen también áreas del derecho en las cuales la responsabilidad de los ciudadanos de conocer y seguir las orientaciones del derecho no depende de un conocimiento o una lectura previa de las normas legales, tal como lo planteara Gardner respecto del Derecho Penal. En algunas áreas el derecho es promulgado no tanto para guiar la conducta futura de las personas, sino para imponer estándares que apuntan a definir disputas las cuales involucran, por su propia naturaleza, factores que es difícil anticipar, tales como los conflictos surgidos a partir de la custodia de

\footnotetext{
${ }^{110}$ Gardner (1994) p. 519

111 Gardner (1994) p. 519.

112 Gardner (1994) p. 519.
} 
los niños después de la disolución del matrimonio, por ejemplo. En dichos casos el establecimiento de estándares generales parece aceptable. Lo mismo ocurre en ciertos contextos donde el derecho es utilizado para fijar parámetros de conducta futuros, pero en los cuales resulta extremadamente difícil definir con anticipación una regla que pueda satisfacer todos los casos que pudieran surgir. Un ejemplo de esta hipótesis es la definición del estándar a partir del cual es determinada la nulidad de un contrato por un vicio de fuerza mayor (force majeure) o por otras consideraciones que se desarrollan o bien se descubren con posterioridad a la celebración del contrato. Hart observa que en todo sistema legal:

“...existe un compromiso entre dos necesidades sociales: la necesidad de que existan ciertas reglas que puedan, en áreas generales del comportamiento, ser aplicadas con certeza por individuos privados sin necesidad de una orientación de agentes estatales o bien sin requerir una ponderación de problemas sociales; y la necesidad de dejar abiertos a la decisión de un funcionario ciertos temas cuya resolución, para ser adecuada, requiere de la existencia de un caso concreto" ${ }^{113}$.

Asimismo, Hart agrega:

"En este aspecto, la Teoría del Derecho tiene una curiosa historia; es adecuado tanto ignorar como exagerar la indeterminación de las reglas legales. Para escapar de esta oscilación entre extremos necesitamos recordar que la incapacidad de los seres humanos para anticipar el futuro, lo cual está en la raíz de esta indeterminación, varía en las distintas áreas de conducta, y que los sistemas legales ofrecen diversas técnicas para tratar el problema"114.

Aparte de la naturaleza esencial del problema y del tipo de respuesta ofrecido por un sistema legal (prohibición penal, responsabilidad por daños, etcétera), el nivel correcto de especificidad de las leyes dependerá del tipo de personas que integran la sociedad que la norma pretenda regular. Esto obliga a considerar debidamente no solo materias tan básicas como el alfabetismo de la población o su nivel educacional, sino también el tiempo y los recursos disponibles para las instituciones de enseñanza del derecho, la disponibilidad de un lenguaje apto para generar explicaciones, y cuán accesibles a las personas son los abogados y otros profesionales del derecho quienes, a un costo razonable, pueden ofrecer una interpretación del derecho y prestar asesoría legal ${ }^{115}$. Las autoridades tienen la obligación de proveer de dichos recursos y, donde las capacidades de los ciudadanos se vean disminuidas, buscar una solución al problema, considerando aquello como una parte de su función de promover los valores propios del Estado de Derecho. Esta responsabilidad se potencia aún más en la medida que las leyes existentes y los proyectos de ley, en general, no se condigan con la costumbre o con las comúnmente conservadas intuiciones morales. Finalmente, se

\footnotetext{
${ }^{113}$ Hart (1994) p. 130.

${ }^{114}$ Hart (1994) pp. 130-131.

115 Finnis (1980) p. 271.
} 
podrían considerar las capacidades de los jueces y otros funcionarios estatales en una jurisdicción particular y sus correspondientes recursos institucionales. Sin embargo, ¿hasta qué punto puede estimarse que los jueces y otros funcionarios públicos manejan y aplican correctamente un complejo y vasto conjunto de regulaciones? ¿En qué medida puede creerse que jueces y funcionarios estatales ejercitan de forma justa e imparcial su discrecionalidad cuando la norma solo contiene estándares? Las respuestas a estas preguntas son muy importantes al momento de decidir cómo generar normas jurídicas dotadas de suficiente claridad.

Timothy Endicott ha hecho una comparación muy útil. Él ha comparado la función orientadora del derecho con un mapa ${ }^{116}$. Un mapa es útil en la medida que pueda orientar a quien lo usa a llegar a su lugar de destino. Para lograr aquello, el mapa no necesariamente debe describir cada mínimo detalle de la ruta. El nivel de detalle requerido dependerá de la ubicación del viajero y del momento del trayecto. Cuando son usados mapas digitales computarizados es posible incrementar o disminuir la magnitud del detalle. Lo mismo ocurre con el derecho. Así, el nivel de especificidad de una ley dependerá -tal como lo señalamos anteriormente- de la materia regulada, del carácter de la sanción penal o civil impuesta, de la disponibilidad de profesionales del derecho, entre otras cosas. Platón ha resumido muy bien el punto: "es infantil procurar brevedad o bien extensión al momento de redactar una ley escrita. Mi opinión es que no hemos de escoger la opción más breve ni la más extensa, sino la mejor" ${ }^{\prime 17}$.

\section{¿ES EL JUEZ CAPAZ DE REPRODUCIR LA CLARIDAD NORMATIVA PROPIA DEL DERECHO LEGISLADO? UN ARGUMENTO DESDE LA NOCIÓN DE ESTADO DE DERECHO}

La virtud de la claridad es lograda de mejor forma a través de la legislación; esto es, a través de la formulación canónica de reglas generales, como aquellas producidas por las legislaturas occidentales en códigos y leyes. En los países regidos bajo un sistema de common law, los jueces también dictan derecho por medio de la creación de precedentes judiciales y su posterior seguimiento. Sin embargo, es necesario decir que la naturaleza y la forma de este proceso son muy controversiales. La producción judicial de normas jurídicas es una forma inferior de generar legislación en cuanto pone en riesgo importantes valores que forman parte del Estado de Derecho. La legislación en sentido propio es requerida por la virtud de la claridad normativa así como por los principios estratégicamente protegidos por la claridad: irretroactividad, promulgación y generalidad.

Una forma de apreciar las diferencias entre common law y legislación es a través de ejemplos. Revisando estos ejemplos podremos encontrar numerosos casos de leyes claramente redactadas en contraste con precedentes judiciales cuyos razonamientos son oscuros o poco claros, incluso incoherentes. Pero, por el contrario, también es posible encontrar legislación pobremente redactada y áreas del common law dotadas de admirable claridad y muy bien comprendidas por la comunidad jurídica. De esta forma, es posible encontrar un

116 EndicotT (2000) p. 203.

117 Platón, Las Leyes (Libro IV). 
amplio material que pueda sostener los dichos de Lord Reid, quien comparaba las reglas producidas por el common law con un "antiguo y valioso producto hecho a mano" en oposición a las reglas producidas por la legislación, las cuales equivalían a "defectuosos productos de la tecnología moderna"118. Asimismo, Frederick Pollock señalaba que "el parlamento generalmente modifica e introduce cambios en la legislación para peor, y... la tarea de los jueces era limitar al máximo las interferencias producidas por estos cambios"119.

Esta falta de confianza expresada por Pollock respecto tanto del órgano legislativo, el parlamento, como de la legislación en sí misma representan una creencia generalizada en el mundo de los abogados que ejercen dentro del sistema de common law, así como de los profesores que lo enseñan. Esta creencia tiene una profunda raíz histórica. Por ejemplo, en su clase inaugural en Oxford, el célebre Blackstone alabó la claridad del common law comparándolo con las desacreditadas y complejamente redactadas leyes de su tiempo:

"Los errores que han surgido a partir de modificaciones injustificadas de nuestro derecho son tan obvios que es difícil cuestionar su existencia; y como ellos son consecuencia de la defectuosa educación de nuestros senadores es una materia digna de pública atención. Con el common law de Inglaterra ha ocurrido lo mismo que con nuestros viejos y venerables edificios de los tiempos antiguos, los cuales han sido rediseñados y nuevamente adornados por hombres imprudentes e inexpertos con el ímpetu propio de la modernidad. Como consecuencia de aquello, la simetría de aquellos monumentos es destruida, sus proporciones distorsionadas, y su grandiosa simplicidad reemplazada por complejas novedades. Digámoslo honestamente, todas las cuestiones intrincadas, los problemas de interpretación, las inútiles sutilezas, y el retraso en la acción de la justicia (el cual ha generado tantas desgracias tanto a los ingleses como a los tribunales) han sido consecuencia no del common law, sino de las innovaciones introducidas por medio de la legislación dictada por el parlamento..."120.

Blackstone criticó el estado de la legislación de su tiempo fundado en la idea de que parte del parlamento literalmente ignoraba las leyes del país, proponiendo que toda persona que aspirara a formar parte del parlamento estudiara previamente las leyes de Inglaterra $^{121}$. Asimismo, sir Edward Coke fustigó el Estado del Derecho legislado de su tiempo, en el cual abundaban "disposiciones y adiciones que muchas veces eran escritas o corregidas por hombres de poco o ningún criterio jurídico", añorando aquellos días en que "las leyes eran dictadas por personas que tenían un conocimiento previo y perfecto de las normas del common law, el que era considerado debidamente antes de legislar sobre la materia" ${ }^{22}$. Con posterioridad a Blackstone y Coke, importantes juristas del ámbito del common law mostraron cierto desdén hacia el derecho legislado, expresando sin ambages su preferencia por el derecho producido por los jueces (Bentham es una notable excepción en este

\footnotetext{
118 Lord ReID (1972) p. 28.

${ }^{119}$ Pollock (1882) p. 85.

${ }^{120}$ Blackstone bk I, secc. 1.

${ }^{121}$ Blackstone bk I, secc. 1.

${ }^{122}$ Coke (1602) (citado por Blackstone, p. 119).
} 
aspecto). No es mi propósito aquí considerar si la posición adoptada por dichos juristas es justificada, o bien si los postulados de Blackstone han sido cumplidos hoy, cuando muchos miembros del parlamento son abogados o bien son asesorados por un numeroso staff de profesionales en sus labores legislativas.

Mi tesis central parte de un supuesto diferente. Tiene como base la proposición de Hart de que el paso de una sociedad prejurídica a una con un sistema legal específico requiere de la adopción de reglas que regulen el cambio, reglas que permitan a ciertos funcionarios estatales dotados de autoridad cambiar las reglas jurídicas que ordenan la socie$\mathrm{dad}^{123}$. La característica más importante de la visión moderna acerca del common law es el reconocimiento de la facultad que tienen los jueces para producir derecho por sí mismos. Sin embargo, las visiones más tempranas acerca de dicho régimen sostienen que los jueces no crean el derecho; por el contrario, las decisiones judiciales que responden a un caso concreto ponen en evidencia cuál es el derecho pero ellas no constituyen el derecho ${ }^{124}$. No ahondaré aquí sobre las difíciles interrogantes que surgen al analizar dichas visiones tempranas del common law (acerca si el derecho es creado o descubierto, o hasta qué medida está sujeto a cambios) ni tampoco el objetivo de este ensayo es contrastar la visión temprana con aquella más moderna. Sin embargo, se hace necesario entender una importante diferencia entre ambas, la que será analizada en profundidad más adelante. Me refiero al carácter de la doctrina del precedente, la cual sostiene que las sentencias dictadas por los jueces en casos previos deben ser consideradas en principio correctas a partir de los hechos que constituyeron el caso, a menos que el tribunal decida en contrario. La visión más temprana del common law siempre consideró que un precedente podía estar equivocado; lo que realmente definía la obligatoriedad del precedente no era el precedente en sí, sino el consenso existente en torno a él entre los miembros de la comunidad jurídica. Ese consenso era lo que definía su obligatoriedad, y no la existencia de una sentencia o bien de varias sentencias resueltas en un mismo sentido ${ }^{125}$. Tanto la visión temprana como moderna del common law comparten la idea de que este surge a partir de decisiones judiciales o bien de la autoridad de los comentadores u otros profesionales destacados, y no como el acto de un rey o bien de alguna otra autoridad o institución dedicada a la producción del derecho.

Mi tesis central es que el Estado de Derecho, en cuyo corazón se encuentran los valores de la claridad, generalidad, promulgación e irretroactividad, exige necesariamente un sistema de separación de poderes en el cual la legislatura sea la principal responsable de la producción del derecho. La alternativa a esta propuesta no es un sistema de common law considerado bajo el prisma de la visión más temprana, sino la visión moderna que llama al juez a producir el derecho a través de la creación, modificación y derogación del precedente. Yo acepto que los jueces puedan producir derecho e introducir cambios al interior del sistema jurídico por medio de las mencionadas técnicas, pero, y esta es mi posición, dicha forma de producción del derecho debe considerarse inferior a aquella que ocurre al interior de un parlamento y, además, es altamente deficiente desde la perspectiva del Estado de De-

\footnotetext{
${ }^{123}$ Coke (1602) (citado por Blackstone, p. 119).

${ }^{124}$ Lamond (2005) p. 24; Postema (1986), p. 1.

125 LAMOND (2005) p. 24.
} 
recho. Mi tesis no está fundamentada en una suerte de comparación técnica entre una ley y una regla establecida por una sentencia judicial; por el contrario, está basada en un criterio sustantivo: la necesidad descrita por Hart de disponer de instituciones y funcionarios dotados de autoridad para cambiar el derecho legislado de acuerdo a las reglas establecidas previamente para tal efecto.

Raz ha señalado que todo sistema legal necesariamente requiere de instituciones llamadas a aplicar el derecho, a aplicar reglas pre-existentes. Sin embargo, el mismo Raz señala que es posible concebir un sistema legal sin instituciones llamadas a crear y producir derecho ${ }^{126}$. "La clave de nuestra noción de un sistema institucionalizado son las instituciones que aplican el derecho y no aquellas que lo producen"127. Cuando Raz hace esta afirmación, lo hace teniendo en vista objetivos diversos de los míos; su preocupación central es la identidad de los sistemas legales y la naturaleza sistemática del derecho. Asimismo, su metodología busca definir aquellos elementos lógicamente necesarios y suficientes para la existencia de un sistema legal, desarrollando de esa forma una teoría "general en cuanto cierta respecto de todos los sistemas legales" 128 . Sin embargo, resulta igualmente instructivo analizar la propuesta planteada por Raz de que un sistema legal puede existir sin un órgano legislador. Siguiendo el razonamiento de Raz, podría existir un sistema legal sin necesidad de que existan reglas para introducir cambios en él. Considerando que las instituciones llamadas a aplicar el derecho deben aplicar reglas preexistentes, no sería necesario que esas reglas proviniesen de una determinada institución (así, por ejemplo, ellas podrían estar escritas en una tabla de piedra o bien tener su origen en la costumbre). De esta forma, la falta de reglas para el cambio no necesariamente significaría la completa ausencia de cambios legales; las normas consuetudinarias, por ejemplo, podrían experimentar el proceso de lenta generación y desuetudo descrito por Hart cuando analiza las características propias de los sistemas prejurídicos. Pero en la ausencia de reglas para el cambio, ninguna persona o institución tendría autoridad para cambiar el derecho a través de deliberados actos de legislación.

Si ese tipo de sistema legal pudiera existir, este sería un modelo defectuoso y no constituiría el caso central de un sistema legal. Para Hart, la ausencia de reglas para el cambio era el sello propio de toda sociedad prejurídica, y la adopción de dichas reglas era el requerimiento básico para que esa sociedad evolucionara hacia un sistema legal. Hart, en repetidas ocasiones, conectó la idea de reglas para el cambio con los conceptos de legislación y legislatura: "las reglas podrían, junto con especificar quiénes están llamados a legislar, determinar también en términos más o menos rígidos el procedimiento a seguir por la legislación"129; "es característico de un sistema legal el que las nuevas reglas legales sean introducidas y las viejas derogadas o modificadas por medio de un acto de legislación (enactment) ${ }^{\prime 130}$. Pero ¿qué ocurriría si un sistema legal diera a las instituciones llamadas a ejecutar el derecho la potestad para cambiar las normas jurídicas (las reglas preexistentes, cualquiera fuese su origen institucional) durante la tramitación de una disputa judicial?

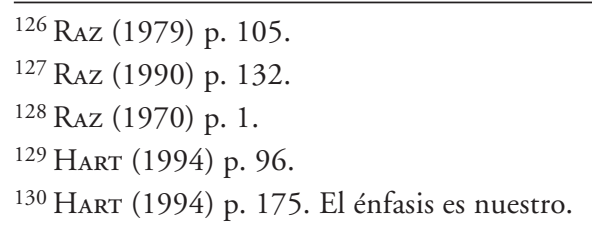


Esto es, precisamente, lo que la visión moderna del common law contempla. De acuerdo a esta visión, los jueces pueden producir derecho a través de la creación, modificación o derogación de los precedentes. No todas las decisiones de los jueces que crean, modifican, o derogan precedentes tienen la intención de producir derecho, pero algunas de ellas sí. Si este fuese el único modo de introducir cambios en un sistema legal, habría poderosas razones para dudar de que esta decisión apunte a mejorar los defectos del stasis en un sistema prelegal, proveyendo los medios efectivos para "deliberadamente adaptar las reglas a circunstancias que son cambiantes, ya sea eliminando reglas anteriores o bien introduciendo nuevas"131. Las dudas surgen no de la capacidad o conocimiento de los jueces, sino del solo hecho de combinar las funciones de juzgar y legislar en una sola institución, y de las implicancias que ello tiene para el Estado de Derecho.

Pero dejemos de analizar el problema dentro del modelo de un sistema jurídico sin una institución encargada de legislar propuesto por Raz, y pasemos a analizar la cuestión dentro de la concepción moderna de common law en la cual el juez tiene facultades para crear el derecho o bien modificarlo como preludio a su aplicación a un caso concreto. Una de las principales preocupaciones desde la perspectiva del Estado de Derecho, y que ha sido identificada por numerosos autores, es que los cambios introducidos por los jueces a la legislación en un caso concreto tienen efectos retroactivos respecto de las partes. En algún sentido, este es un problema que afecta a todos los sistemas jurídicos, en la medida que es producido por la relativa indeterminación del lenguaje de la ley, el que consecuentemente requiere de una interpretación, sea esta producida por el propio legislador o bien por otra autoridad. Esa nueva interpretación de una ley tiene, en alguna medida, efecto retroactivo para las partes afectadas, e incluso podría llegar a producir efectos legislativos en cuanto interpreta una ley cuyo texto es vago, o en la medida que complete lagunas o vacíos legales. En ese sentido, dicho acto es eminentemente productor de derecho. Pero la magnitud de este problema se ve dramáticamente incrementada en un sistema de common law. En un sistema moderno de common law, un juez, al momento de interpretar el texto de una ley que es vaga, por ejemplo, debe considerar no solo la propiedad y la justicia de la interpretación para las partes del caso particular, sino que también (a) el efecto que su decisión genere para otras partes en futuros juicios, y (b) cuán apropiada es la interpretación en cuanto regla general o estándar. Asimismo, en algunos casos, la responsabilidad de un juez del common law se extiende más allá, no solo interpretando la ley, sino definiendo si mantener o no un precedente. En este último caso, el juez también debe analizar si el cambio introducido en el sistema de precedente es propio y justo en relación tanto con las partes del caso como con futuros casos. Por tanto, la obligación de un juez de common law de aplicar el derecho resolviendo un caso concreto está en permanente tensión con su obligación de producir derecho. Ambas se mueven en direcciones opuestas. Cada cambio que el juez introduce en la legislación afecta el principio de irretroactividad, tan preciado para el Estado de Derecho. Aún más, entre más profundo sea el cambio introducido por el juez, mayores serán los costos en términos de predictibilidad. El juez debe escoger, al final, entre introducir cambios beneficiosos en la legislación e imponer una interpretación que producirá efectos retroacti-

${ }^{131}$ HarT (1994) p. 93. 
vos para las partes del caso. Este dilema existe incluso en aquellos sistemas jurídicos en que los tribunales son considerados instituciones que se limitan a aplicar el derecho; de tal manera que las oportunidades para introducir cambios a la legislación se ven dramáticamente disminuidos por el interés en preservar el principio de irretroactividad de la ley. Si bien la legislación en cuanto fuente de derecho no elimina las dificultades que surgen de la indeterminación del texto de una ley, ella promueve la irretroactividad y evita la tensión entre dicho principio y la necesidad de introducir cambios en la ley, la que se produce cuando las funciones de juzgar y legislar se combinan en una sola institución.

La producción legislativa del derecho promueve los valores de claridad y estabilidad dado que las legislaturas actúan bajo iniciativa propia, pudiendo modificar varios textos legales simultáneamente. Muchos aspectos del derecho están interconectados de forma compleja y muchas veces oculta. Luego, una adecuada modificación legal implicará la introducción de cambios simultáneos en distintas áreas del derecho, muchas veces en áreas que no parecen relacionadas. Por ejemplo, una modificación en la ley de quiebras requerirá una modificación en el régimen legal de los seguros y contratos. La legislatura tiene la capacidad para reformar el derecho de forma simultánea, pero los tribunales pueden introducir solamente cambios parciales y progresivos. Además, en cuanto los tribunales pueden actuar solamente en respuesta a la iniciativa de terceros, su capacidad para introducir cambios a la legislación va a ser limitada por las circunstancias bajo las cuales un caso emerge. Este mecanismo de producción del derecho impide alcanzar un deseable nivel de estabilidad en dos sentidos. Por un lado, en cuanto los tribunales no pueden revisar decisiones adoptadas previamente por iniciativa propia, aquellas decisiones gozan de una cierta permanencia en el tiempo en comparación con el derecho legislado, el cual es, en principio, susceptible de ser revisado solo cuando la necesidad aparece. Por otro, producir derecho a través del efecto acumulado de precedentes implica un compromiso con un proceso continuo de cambios legales. Por el contrario, las legislaturas son capaces de establecer reglas claras y suficientes en el presente para resolver casos en el futuro. Estas reglas son escogidas como los mecanismos de solución hasta que la legislatura por medio de otro acto decida modificar o derogar la norma. Finalmente, las reglas producidas por la legislatura pueden proveer de normas de carácter transitorio con el propósito de evitar las complicaciones surgidas de la retroactividad.

Todo esto nos demuestra que las legislaturas se encuentran en una posición preferente para promover la virtud del conocimiento de la ley, conocimiento que se expresa a través del acto de promulgación. En contraste, el common law no es, estrictamente hablando, promulgado. Aunque el common law está reflejado en fuentes escritas tales como las recopilaciones de casos, el derecho allí contenido no está redactado en términos canónicos. Tal como autores más antiguos lo señalaban, el common law es lex non scripta, derecho noescrito $^{132}$. Lo que la legislación precisamente hace es darle al derecho una forma lingüística de carácter canónico. Pero considerando la crítica formulada por Blackstone hacia el derecho legislado, es posible preguntarse por qué esta forma lingüística específica sería deseable, comparando las técnicas de redacción confusas usadas por el legislador con la "majestuosa simplicidad" del common law. En este punto es necesario considerar que la claridad atri- 
buida por Blackstone al common law se debe en mucho al trabajo de sus comentadores y de profesores en las escuelas de derecho, quienes han compilado y sintetizado las recopilaciones de casos existentes. De esta forma, la simplicidad admirada por Blackstone podría ser realmente invisible a los ojos de un ciudadano común y corriente, e incluso a los ojos de abogados y jueces en el momento en que ellos buscan descubrir la regla detrás de muchos casos. Es perfectamente posible decir que, generalmente, ellos podrán encontrar más claridad y simplicidad tratando de descubrir el derecho en una ley que tratando de hacerlo por medio de la lectura de muchos y complejos casos, aun cuando esta comparación, por supuesto, depende de muchas circunstancias. Sin embargo, una ley siempre constituirá un esfuerzo por parte de la autoridad para dar a conocer de forma pública el contenido del derecho. Asimismo, la ley muestra de forma anticipada los estándares que serán utilizados por los jueces para decidir casos e imponer penas penales y civiles a quienes se encuentran sujetos a ella. Esta es la idea básica detrás de la promulgación. Por el contrario, la mentalidad que subyace el common law no requiere necesariamente actos de promulgación; no existe la necesidad de proclamar de manera pública las razones por las cuales un caso fue decidido de forma previa al surgimiento de otros casos futuros ${ }^{133}$.

El hecho de que el common law adquiera su forma y significado por medio de las síntesis efectuadas por los comentadores y por los profesores de derecho es un tema estudiado profundamente por Grant Lamond ${ }^{134}$. Él cuestiona la visión tradicional de que los precedentes crean las reglas en el common law. De acuerdo a dicha visión, la ratio de un caso es un tipo de regla que el juez aplica a un conjunto de hechos para determinar, o bien justificar, la decisión adoptada por medio de una sentencia. Entendido de esta manera, el common law es un tipo de razonamiento jurídico basado en reglas, aunque es uno en el cual la responsabilidad de aplicar las reglas es acompañada del poder para modificarlas o, incluso en algunas circunstancias, derogarlas. Lamond argumenta que los precedentes individualmente considerados no crean reglas y que, por tanto, el common law no sería un tipo de razonamiento basado en reglas, sino uno que resuelve conflictos jurídicos caso a caso ${ }^{135}$. Para Lamond, la restricción impuesta por un precedente previo no es realmente vinculante, en la medida que un juez puede, de acuerdo a la visión moderna del common law, aplicar el precedente siempre que él entienda que es correcto, pudiendo incluso derogarlo. De esta forma, un juez podría aplicar a un conjunto de hechos similares a los de un caso previo una regla distinta ${ }^{136}$. Luego, el juez posterior no está realmente obligado a aceptar la ratio propuesta por el juez anterior en la medida que su decisión, hipotéticamente, no produjera un resultado diferente en el caso previo. De hecho, el juez posterior puede mejorar o bien reformular la regla, o incluso puede derechamente ofrecer una nueva, siempre

\footnotetext{
${ }^{133}$ Esta mentalidad es más aceptable en sociedades realmente estables, donde el derecho derivado de los casos judiciales seguía las costumbres de los gobernados, como ocurría con el original ethos del common law. Por el contrario, es menos aceptable en sociedad diversas como las nuestras, pletóricas de profundos y complejos problemas legales, en las que los contratos celebrados adquieren una importancia capital en desmedro de la reglas de la costumbre.

${ }^{134}$ Lamond (2005) p. 1.

${ }^{135}$ Lamond (2005) p. 1.

${ }^{136}$ LAMOND (2005) pp. 3 y 14.
} 
que la aplicación de ella no hubiese producido un resultado distinto en el caso anterior ${ }^{137}$. Lamond cree que su visión respecto de este tema es más adecuada que la visión tradicional para explicar algunos aspectos del common law, particularmente aquellos relacionados con la supuesta obligatoriedad del precedente ${ }^{138}$. La visión tradicional del common law postula que el arte de distinguir un caso respecto de otro está centrado en el análisis de la ratio del juez anterior; el juez posterior puede refinar dicha ratio o bien modificarla de forma más o menos notoria. Esta práctica sería el medio a través del cual el common law evolucionaría. De acuerdo a esta forma tradicional de ver el common law, el distinguir entre casos sería algo absolutamente excepcional. El juez posterior requeriría de una razón suficiente para hacerlo, de una razón que realmente justificara el cambio de la ratio previa. Lamond opone a esta visión tradicional la suya propia. De acuerdo a esta, el distinguir un caso de otro anterior no tiene que ver con la ratio; por el contrario, tiene que ver con los hechos. Un juez posterior podría distinguir su caso del anterior sencillamente porque los hechos del suyo son distintos de aquellos del caso previo. Por tanto, al no existir una analogía perfecta entre ambos casos, no correspondería la aplicación de la ratio anterior. Para Lamond, el análisis de los hechos define cuán vinculado se encuentra el juez posterior al precedente. Esta forma de análisis, concluye el autor, es la razón de la lenta y discursiva evolución del common law.

No tenemos el suficiente espacio en este ensayo para proveer una completa evaluación de la tesis de Lamond, o bien para considerar todas sus consecuencias. Sin embargo, uno de los elementos centrales de su planteamiento es particularmente relevante a la hora de revisar si la legislación puede satisfacer el requerimiento de claridad impuesto por el Estado de Derecho. La práctica de los jueces en el common law es proveer una suficiente justificación para la decisión adoptada, pero no es ni requerido ni esperado de ellos que justifiquen su decisión sobre la base de los elementos necesarios y constitutivos de la regla aplicable ${ }^{139}$. Por tanto, existe una diferencia fundamental entre la ratio de un caso y una regla proveniente de una ley, diferencia que va más allá del hecho de que un juez no esté obligado a establecer la regla con precisión, de forma que no existe la necesidad de entender o bien de interpretar las palabras utilizadas de manera estricta. La diferencia más profunda estriba en el hecho que la ratio de un caso individual no puede ser considerada realmente como una regla con alcance general en la forma en que una ley sí lo es ${ }^{140}$. Una ley establece de forma lógica el conjunto de elementos constitutivos de una regla, así como su estructura y las relaciones entre sus condiciones, excepciones, y el resto de sus elementos. En el common law es posible encontrar, si es que ello ocurre, este mismo grado de precisión y definición solo en los comentarios y tratados ${ }^{141}$. El método utilizado por los profesores que escriben dichos comentarios y tratados es simplemente sintetizar los resultados de un número determinado de casos, síntesis que muchas veces abarca solamente los resultados y no necesariamente la ratio detrás de ellos. Por supuesto que es también posible encontrar lúcidas sistematizaciones de casos anteriores en sentencias redactadas de forma inteligente.

\footnotetext{
137 LAMONd (2005) pp. 12-13.

138 LAMOND (2005) pp. 9-13.

${ }^{139}$ LAMOND (2005) pp. 1 y 18.

${ }^{140}$ LAMOND (2005) pp. 18-19.

${ }^{141}$ Lamond (2005) pp. 21-22.
} 
A pesar de ello, deberíamos ser sumamente cautos al momento de considerar dichas sistematizaciones como reglas específicas.

\section{CONCLUSIÓN: EL VALOR DEL DERECHO LEGISLADO FRENTE AL DERECHO PRODUCIDO POR LOS JUECES}

El método sobre el cual trabaja el common law no es un proceso en el cual los agentes productores del derecho, los jueces, promulgan reglas que se distinguen tan solo accidentalmente de aquellas generadas por las legislaturas. Por el contrario, los razonamientos que sustentan una sentencia no son reglas de alcance general promulgadas por quien tiene la potestad legisladora. Si una regla del common law es clara, lo es tan solo en la medida que los comentadores (y ocasionalmente jueces con alta preparación jurídica) puedan producir una síntesis de casos que sea similar al tenor de una regla. Usando la analogía de Lord Reid, este proceso de desarrollo jurídico podría eventualmente generar un cuerpo de doctrina con las cualidades de aquellos productos antiguos fabricados a mano. Pero muchas de las sentencias que contribuyan a refinar o modificar esa doctrina construida a lo largo del tiempo tendrán fundamentos totalmente nuevos, o bien producirán efectos de carácter retroactivo para las partes del caso. Por otro lado, la justa preocupación por minimizar esos efectos retroactivos impondrá sustanciales restricciones al desarrollo y evolución del common law. Por tanto, la producción del derecho escrito por medio de legislación es la forma más apropiada para tratar de alcanzar la tan deseada virtud de la claridad y promover los valores asociados a ella, tales como la irretroactividad, la generalidad, y la promulgación, aun cuando sus resultados muchas veces carezcan de la "majestuosa simplicidad" hallada en algunas áreas del common law.

\section{BIBLIOGRAFÍA CITADA}

Aristóteles (1923): Nichomachean Ethics (Traducc. JEC Welldon, London, McMillan) $358 \mathrm{pp}$.

Aristóteles (1925): Nichomachean Ethics (Traducc. W.D. Ross, Oxford, Oxford University Press) $277 \mathrm{pp}$.

Austin, John (1832): The Province of Jurisprudence Determined (Edit. W.E. Rumble, Cambridge, Cambridge University Press) 344 pp.

Blackstone, Sir William ([1765-1769] 1979): Commentaries on the Laws of England (Tomo I) (Chicago, Chicago University Press) $496 \mathrm{pp}$.

Endicott, Timothy (2000): Vagueness in law (Oxford, Oxford University Press) 232 pp.

Finnis, John, (1980): Natural law and natural rights (Oxford, Clarendon Press) 442 pp.

Finnis, John (1994): "Natural law and legal reasoning", en George, Robert (edit.), Natural law theory contemporary essay (Oxford, Oxford University Press) 384 pp.

FInNIS, John (1998): Aquinas: moral, political, and legal theory (Oxford, Oxford University Press) 408 pp.

Finnis, John (2007): “On Hart's ways: law as reason and as fact”, American Journal of Jurisprudence, vol. 52: pp. 25-46. 
Fuller, Leo (1969): The morality of law (New Haven, Yale University Press) 262 pp.

Gardner, John (1994): "Rationality and the rule of law in offences against the person", Cambridge Law Journal, vol. 53: pp. 502-512.

Hart, HLA (1958): "Positivism and the separation of law and morals", Harvard Law Review, vol. 71: pp. 593-599.

Hart, HLA (2a edic, 1994): The concept of law (Oxford, Clarendon Press) 315 pp.

LAMOND, Grant (2007): “Do precedents create rules?”, Journal of Legal Theory, vol. 11: pp. $1-24$.

Llewellyn, Karl (1931): "Some realism about realism - Responding to dean Pound", Harvard Law Review, vol. 44: pp. 1222-1256.

Orrego, Cristóbal (2004): "HLA Hart's understanding of classical natural law theory", Oxford Journal of Legal Studies, vol. 24: 287-302.

Platón (2005), Las Leyes (Traducc. T Saunders, London, Penguin) 560 pp.

Pollock, Frederick (1882): Essays on jurisprudence and ethics (London, MacMillan) 383 pp.

Postema, Gerald J. (1986): Bentham and the common law tradition (Oxford, Clarendon Press) $512 \mathrm{pp}$.

RAz, Joseph (1979): "The rule of law and its virtue", en: Raz, Joseph, The authority of law: essays on law and morality (Oxford, Clarendon Press) 360 pp.

Raz, Joseph (1990): Practical reason and norms (Princeton, Princeton University Press) 224 pp.

RAz, Joseph (1996): Ethics in the public domain: essays of on law and morality (Oxford, Clarendon Press) 392 pp.

RAZ, Joseph (2001): Value, respect, and attachment (Cambridge, Cambridge University Press) $188 \mathrm{pp}$.

RAZ, Joseph (2009): Between authority and interpretation: on the theory of law and practical reason (Oxford, Oxford University Press) 424 pp.

Lord Reid (1972): "The judge as law maker", Journal of the Society of Public Teachers of Law, Vol. 22: pp. 22-29.

Santo Tomás de Aquino (1920), Summa Theologica of Saint Thomas Aquinas (Traducc. Fathers of the English Province).

\section{JURISPRUDENCIA CITADA}

House OF LORDS

$R$ (Animal Defenders International) v. Secretary of State for Culture, Media, and Sport [2008] UKHL 15, [2008] 1 AC 1312, [2008] 3 All ER 193

C (un menor) v. Eisenhower [1984] QB 331, [1983] 3 All ER 230 (DC).

\section{NORMAS CITADAS}

Legislación Británica

Offences Against the Person Act 1861, 1861 Chapter 10024 and 25 Vict 